\title{
The anatomy of natural disasters on online media: hurricanes and wildfires
}

\author{
Nicole Olynk Widmar ${ }^{1} \cdot$ Kendra Rash $^{1} \cdot$ Courtney Bir ${ }^{2}$ (D) $\cdot$ Benjamin Bir ${ }^{3} \cdot J_{i n h o ~ J u n g}{ }^{1}$
}

Received: 25 April 2020 / Accepted: 6 August 2021 / Published online: 26 August 2021

(c) The Author(s), under exclusive licence to Springer Nature B.V. 2021

\begin{abstract}
Increasing prevalence and scale of natural disasters fuel the need for new approaches to evaluating, and eventually mitigating, their impact. This analysis quantifies and compares online and social media attention to hurricanes and wildfires over time and geographic space. Hurricanes studied included: Michael, Maria, Irma, Harvey, and Florence. Fires studied included: Woolsey, Mendocino, Carr, and Camp. It was hypothesized that total volume of online media content, measured in posts and mentions, varied measurably over the phases of the disasters. Furthermore, it was hypothesized that the anatomy of the disaster, specifically the number and timing/dates, of posts and mentions varied inside versus outside impacted zones/geographies. Social media content, in sheer volume, related to hurricanes was larger than that devoted to fires. A mismatch between the time periods that people post about natural disasters on social media and the times when aid is needed to rebuild was found. Mentions fell rapidly after landfall for hurricanes, and long before fires were officially contained or extinguished. This rapid fall in media attention may leave directly impacted populations without help and support during the rebuilding process. Greater understanding of volume of posts over time, or the anatomy of disasters in online media space, may help government agencies, private industry, and relief organizations understand public attentiveness before, during, and after various types of natural disasters.
\end{abstract}

Courtney Bir

courtney.bir@okstate.edu

Nicole Olynk Widmar

nwidmar@purdue.edu

Kendra Rash

rashk@purdue.edu

Benjamin Bir

me.benbir@gmail.com

Jinho Jung

jung104@purdue.edu

1 Department of Agricultural Economics, College of Agriculture, Purdue University, 403 West State Street, West Lafayette, IN 47907, USA

2 Department of Agricultural Economics, Ferguson College of Agriculture, Oklahoma State University, 529 Agricultural Hall, Stillwater, OK 74078-6026, USA

3 Stillwater, USA 
Keywords Data analytics $\cdot$ Hurricane $\cdot$ Risk mitigation $\cdot$ Social media analytics $\cdot$ Wildfire

\section{Introduction}

Due to expected rises in ocean temperature, it is anticipated that hurricanes will increase in frequency and intensity (Fischetti 2018). On land, climate is becoming hotter and drier, resulting in more frequent and stronger fires (Ortiz 2018). As hazards from natural disasters are expected to impact more people with increasing number and severity of events, new avenues of exploring risk and mitigation communication are evolving. Social media and online content is one such measure that is being used in the "citizen as sensor" approach to public safety issues (Martin et al. 2017).

Although there are many sources for news, online and digital media is unique in allowing for real-time distribution, development, and consumption. While providing a broad literature review of disaster-related communications on Twitter, Son et al. (2019) summarized studies evaluating Twitter usage during disasters. They formed three categories, namely studies focusing on tweet content, studies focusing on Twitter users, and studies focusing on Twitter features. Son et al. (2019) highlight that disaster communication work conducted on Twitter "often overlooks the different phases of disaster events that could influence communication patterns among the public and thus affect how people use Twitter." While focusing on social and online media during a disaster offers usable insights, evaluating communication in preparation phases, as well as during and after the event, would offer a more complete picture.

Gaining understanding of posts/media during disasters enables rapid dissemination of critical information, such as locations for critical rescue efforts and/or directing of aid and medical support, as well as damage assessment. The added value of social listening as a surveillance system for disasters has been documented (Middleton et al. 2014; Imran et al. 2013; Cameron et al. 2012). Previous studies perceived the relationship between ubiquitous characteristic of social media and fundraising potentials for aiding victims. Nagar et al. (2012) found that geographic diffusion of a disaster covers the entire world via social media, which has a significant potential of developing universal fundraising activities.

This analysis quantifies and compares online attention to hurricanes and fires over time and geographic space. This study quantifies the volume, timing, and focus of online media in the time periods before, during and after Hurricanes Irma, Maria, Michael, Harvey, and Florence in addition to online media related to the Woolsey, Mendocino, Carr, and Camp fires. It was hypothesized that total volume of content, measured in posts and mentions related to individual natural disasters, varied measurably over the phases of the disaster. Furthermore, it was hypothesized that number and timing of posts and mentions within versus outside impacted zones/geographies varied. Additionally, whether the amount of attention a hurricane receives online is compared to the amount of attention a hurricane receives in terms of funding for disaster recovery and aid to victims was evaluated.

\section{Background information}

Beyond the immediacy of communication during the disaster, understanding the patterns, verbiage, and intentions of communication surrounding disasters could enable the development of risk mitigation and preparedness of disaster management. Twitter has been studied 
extensively in the areas of emergency management (Panagiotopoulos et al. 2014, 2016). Martin et al. (2017) found that during Hurricane Matthew, peak Twitter response occurred leading up to the hurricane, and quickly decreased after the passage of the storm. Using Twitter, they were able to assess the evacuation response of residents affected by Matthew (Martin et al. 2017). Yin et al. (2012) also showed a positive correlation between peaks in the volume of tweets and the magnitude of 2010 earthquakes in Christchurch, New Zealand. Using Twitter data, Moore and Obradovich (2020) augment current flood standards based on tidal gauges at the county level. Based on their analysis of flood-related posts, they found that some counties experienced nuisance flooding that did not register using standard measures, which has implications for planning and response purposes (Moor and Obradovich 2020).

Studying hurricanes Irene and Sandy as well as tornados and a flood in Louisiana, Niles et al. (2019) found that those with an average-sized Twitter network (people they followed and followers) tweeted more during a natural disaster. Tweets from the average person outnumbered Twitter influencers during the disasters studied. Increases in Twitter use during natural disasters are important information for government agencies and relief organizations that are trying to provide information for those impacted, as well as information on how to help for those who are not. Twitter itself provides tips on Tweeting during a natural disaster through the company's blog, which includes suggestions like following news agencies and using the right hashtags (Reen 2018).

Studying hurricane Sandy, Wang and Zhuang (2017) found that news agencies tweeted more than governmental organizations and non-governmental organizations. Also studying hurricane Sandy, Pourebrahim et al. (2019) found that Twitter users reported receiving news from Twitter sources including, friends, family, and government agencies at a higher rate than non-Twitter users. As the information is distributed to a wide audience, people comment on and contribute additional information to the original source, creating a living breathing document with various viewpoints. For example, during hurricane Sandy in 2012, many states experienced power outages making traditional means of communication difficult, but people continued to use social media for information (Sadri et al. 2018). Using machine learning and Twitter data, Sadri et al. (2018) determined the evolution of communication patterns during hurricane Sandy. They identified three phases-warning, response, and recovery. They also concluded people were concerned about the storm's location, media coverage, and the activities of high-profile people including political leaders and celebrities (Sadri et al. 2018).

Facebook studies are also prevalent in the emergency response domain. Pogrebnyakov and Maldonado (2018) studied nearly a million messages from 997 Facebook pages of US police departments to study text complexity relative to emergency stage. For example, Sakaki et al. (2010) used Twitter data to estimate a spatiotemporal model for earthquake events. Their model worked better at estimating centers for earthquakes, and their accompanying system was able to notify people faster than the Japan Meteorological agency (Sakaki et al. 2010). Earthquake damage intensity was benchmarked using social media in several studies (Avvenuti et al. 2017; Mendoza et al. 2019; Earle 2010). In addition, according to Alexander (2014), after 50 min of an earthquake in northern Italy in 2012, a rapid, clear and relatively comprehensive picture of the earthquake became available with the help of social media. Beyond earthquakes, studying hurricane Sandy, Kryvasheyeu et al. (2016) used Twitter data and a spatial-temporal model to compare the online response of 50 metropolitan areas of the USA and found a strong relationship between proximity to Sandy's path and hurricane-related Twitter activity. Kibanov et al. (2017) used Twitter data 
to compare the ability of social media posts to complement and supplement information provided by NASA satellite imagery to track haze and fire incidents in Indonesia.

A significant body of literature has focused on the impact and efficacy of official government social media use for information dissemination. In an analysis of public relations best practices, Freberg et al. (2013) identified "good" social media crisis messages as containing links to further information, use of a strong voice, and multimedia. Liu et al. (2018) found that government organization crisis communication strategies focus on information over blame mitigation, and that Twitter enhances government organization-public crisis communication. Official social media posts as well as citizen posts are interconnected as they are often re-posted and commented on to create the body of natural disaster-related social media.

Existing studies on individual natural disasters spur questions about the anatomy of a category of natural disasters in online and social media broadly. Is the development of social media in response to a hurricane, for example, reflective of hurricanes generally or only that particular hurricane? Hurricanes are increasingly widely publicized; the "terrible trio" of Hurricanes Harvey, Irma, and Maria propelled 2017 to the costliest hurricane season since record keeping began in 1851 at approximately $\$ 370$ billion dollars (Halverson 2018). For the first time in recorded history, three Category 4 hurricanes made landfall in the USA, namely Harvey, Irma, and Maria, and five total Category 5 landfalls took place across the Caribbean (Blake 2018).

The effect of the population impacted by the natural disaster, as well as the duration and strength of the event, is likely to influence monetary aid, as well as social media presence. These two factors came to a head when hurricane Harvey stalled over Houston Texas. Houston is the fourth largest metro area in the USA and has experienced large amounts of suburban sprawl resulting in the removal of grass and marshes that would help prevent (Halverson 2018). This geography coupled with a vast plume of low-level moisture combined with a high-pressure system created a storm that resulted in 25 trillion gallons of freshwater falling on the county, 91 fatalities, and 200 billion dollars in damages - 40 million more than hurricane Katrina (Halverson 2018). Other geographic features, such as being an island, also influenced the impact of recent hurricanes. Hurricane Irma hits the island of Puerto Rico, killing 97 people (Halverson 2018). Unfortunately, due to difficulties rebuilding structures, and getting aid to the island, it is expected that additional 500 deaths can be attributed to the direct aftermath (Halverson 2018).

In comparison with hurricanes, which have a predicted landfall that is determined sometimes weeks in advance (Cangialosi and Berg 2012), fires appear sporadically. Although weather conditions and fuel buildup may help predict the chances of fires occurring (Andrews et al. 2007), there is less warning than for hurricanes. Evaluating both hurricanes and fires allows researchers to begin determine factors that influence social media response.

\section{Materials and methods}

Data collection facilitated by in-depth Internet/web searches, often focused on media sources and news outlets, has long been utilized in social science research (for example, via platforms such as LexisNexis (2019). This analysis employed the Netbase platform, which offers search and analysis capabilities for online media, including blogs, forums, consumer reviews, Twitter, Instagram, News, and other media (Netbase 2018). Netbase ranks among 
the top social listening platforms, and has been used for research purposes as well as quantifying interest and sentiment for product development (Carr et al. 2015). Searches across countries and in multiple languages are technologically possible, although limitations surrounding language interpretation, like slang, shorthand, sarcasm, and cultural context must be acknowledged. For this analysis, the geographic area for all searches employed was limited to the USA and US Virgin Islands; posts in English were studied exclusively.

Online search results within search parameters associated with five hurricanes and four wildfires were studied during the time period of 9-16-2016 through 12-16-2018. The 27-month time period studied offered sufficient time for in-depth comparison during an abnormally impactful hurricane period in the USA. Given the fluidity of data collected through social media posts as they may appear, be removed, and/or be reinstated, data collection dates were documented. Data were downloaded and summarized on December 15-16, 2018.

\subsection{Parameterization of searches and analysis of hurricanes}

By 1979, the USA was using male and female names to identify tropical storms and hurricanes in both the Pacific and the Atlantic (NOAA 2018a). This nomenclature was adopted to avoid previous confusion with the numbering system when storms would occur simultaneously (NOAA 2018a). Due to the use of common names to identify individual storms, careful attention was needed to determine the word set to establish the general hurricane data set. By including, for example, the name Michael (a named hurricane), all posts authored by or talking about a person named Michael would be found, as well as hurricane Michael (the targeted media). However, including the search term hurricane Michael would not generate additional data points not already captured by the word hurricane. Therefore, the terms used to determine the base hurricane data set included: Hurricane, \#Hurricane, hurricane, and \#hurricane.

Further tuning of the search was done by evaluating individual posts and determining keywords, authors (bots), or domains to exclude. For example, song lyrics such as "rock you like a hurricane" were removed along with references to comic books, Pokémon, and university mascots such as the Tulsa University Hurricanes. Some domains also required extra attention when developing searches to collect the relevant/necessary data. The majority of domains were social media platforms and news sources; however, other blogs such as community.babycenter.com were within the top domains. Upon closer inspection, many of the posts in this particular domain were parents talking about ways to prepare for hurricanes with children, options for evacuations, and other hurricane-related topics. However, some of the posters were describing the behavior of their children as "like a hurricane." Efforts were made to exclude such posts through the exclusion of phrases such as "my little hurricane." All inclusions and exclusions for the hurricane topic are available in Appendix 1 .

Conversations regarding each hurricane may differ, so efforts were made to isolate posts related to each individual hurricane by employing themes, which were essentially filters placed over top of existing search terms. Due to hurricanes having common names, there were challenges with this process beyond simple search engine use. For example, Michael Jordan made a sizeable donation on behalf of hurricane Florence relief and any post/news story/or blog mentioning this would also appear in the hurricane Michael data set, because of Michael Jordan's first name. Researcher inspection of the data set revealed that relatively few posts referenced hurricane Michael without the word hurricane. For example, 
people were more likely to talk about damage caused by hurricane Michael than they were to talk about damage caused by Michael. Therefore, all hurricane themes were created as hurricane (name) and the associated hashtags. For example, the hurricane Michael theme was comprised of Hurricane Michael, \#Hurricane Michael, \#hurricanemichael. The named hurricanes included in this data set were gathered from the NOAA (National Oceanic and Atmospheric Administration) website and include hurricanes Florence, Michael, Maria, Irma, and Harvey (NOAA 2018b). Due to limitations in the available data time frame (27 months prior to collection period), collecting data prior to hurricane Harvey was not possible at the time that the research was conducted.

To allow for comparison across areas of different impact potentials such as in Kryvasheyeu et al. (2016), specific geographic regions were identified. Filters employed included hurricane states, defined as states in which there was a historical hurricane landfall (NOAA 2018c), and non-hurricane states, which included all other states. Hurricane states included Texas, Louisiana, Mississippi, Alabama, Florida, Georgia, South Carolina, North Carolina, Virginia, Maryland, Delaware, New Jersey, Pennsylvania, New York, Connecticut, Rhode Island, Massachusetts, New Hampshire, and Maine. It was hypothesized that those in hurricane-prone areas would have different reactions to new hurricanes, for example, they may show solidarity toward others affected. It was also hypothesized that those affected may use different languages in their posts when compared to non-affected areas. For example, perhaps those immediately affected by the hurricane have more financial- or economicrelated posts that include words such as recover and aid, while those unaffected may have posts such as pray for, thinking of, and hope for. For each individual hurricane, the affected area was determined as the closest major city to the hurricane's landfall by researchers. For example, the affected area for hurricane Florence was Wilmington, North Carolina, USA.

It was also hypothesized that the posts/blogs/news would differ between the time leading up to and following the hurricane. Martin et al. (2017) also used pre- and post-evacuation time periods when studying hurricane Matthew. Two distinct time frames were determined for each hurricane, before the hurricane, and after the hurricane. Hurricanes start as a weaker storm, for example, a tropical storm, and then build into a hurricane which may not make landfall for days, weeks, or ever (Cangialosi and Berg 2012; Hurricanes: Science and Society 2020). Due to their nature, hurricanes are often followed and talked about prior to landfall, therefore it was important to monitor a period of time prior to and during landfall. The time between the formation of each hurricane and the dissipation of each hurricane as defined by the National Hurricane Center Tropical Cyclone report was used to determine the "lifespan" of each hurricane that occurred prior to 2018 (NOAA 2018b). The NOAA cyclone report for 2018 was not yet available at the time of data collection/date setting, so a Federal Emergency Management Agency (FEMA) report was used to establish the lifespan of hurricane Michael (FEMA 2018a), and a combination of news sources was used to establish the lifespan of hurricane Florence (Larino 2018; CBSa 2018). The halfway point for the hurricane's lifespan was determined; the period before each hurricane was calculated by subtracting 30 days from the midway point of the lifespan. To calculate the time frame after the hurricane, 60 days were added to the midway point of the lifespan. For example, the lifespan of hurricane Maria was September 16-30, 2017. The halfway point (if it was an odd number the extra day was included in the before period) was September 23, 2017. Therefore, the time frame before hurricane Maria was determined as August 24, 2017-September 23, 2017, and the time frame after hurricane Maria was determined as September 24, 2017-November 23, 2017. The timeframes for hurricanes are available in Table 1. All search details for each individual hurricane are available in Appendix 2. 
Table 1 Dates designating before and after hurricane and during and after wildfires studied

\begin{tabular}{lll}
\hline Hurricane Florence & Before & August 11, 2018-September 10, 2018 \\
Aurricane Harvey & Before & September 11, 2018-November 10, 2018 \\
Hurricane Irma & After & July 25, 2017-August 24, 2017 \\
Hurricane Maria & Before & August 25, 2017-October 24, 2017 \\
& After & August 8, 2017-September 7, 2017 \\
Hurricane Michael & Before & September 8, 2017-November 7, 2017 \\
After & August 24, 2017-September 23, 2017 \\
Camp Fire & Before & September 24, 2017-November 23, 2017 \\
Carr Fire & After & September 13, 2018-October 13, 2018 \\
& During & October 14, 2018-December 13, 2018 \\
Mendocino Fire & After & Nov 8, 2018-November 25, 2018 \\
& During & November 26, 2018-December 16, 2018 \\
Woolsey Fire & After & July 23, 2018-August 31, 2018 \\
& During & September 1, 2018-October 31, 2018 \\
& After & July 27, 2018-October 04, 2018 \\
\hline
\end{tabular}

Statistical analysis of the number of mentions before and after hurricanes, and during and after fires was completed. The total number of mentions before and after the hurricanes or fires for direct impact states, hurricane/fire states, and non-hurricane/non-fire states were determined. The percentage of posts occurring before and after for each category were calculated, and then statistically compared using the test of proportions. This allowed researchers to determine if the percentage of mentions occurring before and after for the 3 regional categories studied statistically differed. A test of the difference of two proportions $\widehat{p_{1}}$ and $\widehat{p_{2}}$, can be calculated as:

$$
z=\frac{\widehat{p_{1}}-\hat{p_{2}}}{\sqrt{\widehat{p_{p}}\left(1-\hat{p_{p}}\right)\left(\frac{1}{n_{1}}+\frac{1}{n_{2}}\right)}}
$$

given:

$$
\widehat{P_{p}}=\frac{x_{1}+x_{2}}{n_{1}+n_{2}}
$$

where $x_{1}$ and $x_{2}$ are the total number of successes in the two populations (Acock 2018). The tests of proportion were conducted using STATA/SE16 (StataCorp 2019).

\subsection{Financial aid and relief for hurricanes}

There are many organizations aimed at providing relief efforts and monetary support to individuals and families impacted by natural disasters, such as the Red Cross and FEMA. In order to quantify the impact of monetary relief for various natural disasters, researchers 
looked for a source that provided consistent data for the named hurricanes studied. The American Red Cross has monetary data that is updated semi-frequently, providing the number of dollars, donated to a specific cause, across the country. FEMA keeps a public record of information, statistics, and resources for each natural disaster that impacts the USA (or US Territories) (FEMA 2020). The data search began at the FEMA government website (www.fema.gov), using the search toolbar, researchers typed in the name of the natural disaster (ex: Hurricane Maria). For each natural disaster, FEMA has a main website documenting the specific areas that were impacted and the disaster codes associated with each of these areas. Each impacted area is assigned a unique Disaster Declaration Number (DR) by FEMA (FEMA 2009). The DR codes for each hurricane were documented and used as a secondary check that the areas initially used for each disaster were all encompassing. Then, for each hurricane, and each DR area (as recorded by FEMA), there were three numbers recorded for analysis: "Individual Assistance Applications Approved" (FEMA 2019a), "Total Individual \& Household Program Dollars Approved" (FEMA 2019a), and "Total Public Assistance Grants Dollars Obligated" (FEMA 2019b). These numbers were aggregated, by hurricane, and across all DR areas to allow comparisons between online mentions and monetary impact. Economic impact in billions of dollars was obtained for Harvey, Irma, and Maria from FEMA (FEMA 2018b). Economic impact for Florence was obtained from Cooper (2018), and the economic impact of hurricane Michael was obtained from NOAA (2018a, b, c, d).

Statistical analysis was completed by determining the total number of approved assistance applications, the total dollar value for assistance (the summation of total individual households program, and total public assistance), the total dollar value of Red Cross donations, and the total economic impact across the 5 hurricanes studied. The percentage of each category for each hurricane was then calculated. For example, the percentage of total assistance from hurricane Maria out of the total assistance provided for the 5 hurricanes was determined. These percentages were then statistically compared using the test of proportions (Eqs. 1, 2) to determine the rank from highest percentage to lowest percentage. The total number of social media and online media mentions was determined across all 5 hurricanes. Again, the percentage of total mentions was determined for each hurricane and statistically compared to establish a rank of hurricanes from highest percentage of mentions to lowest. The rankings across both the financial measures, and social media data were then compared to establish connections between social media chatter, economic impact, assistance provided, and donations.

\subsection{Providing a comparison among natural disasters: methodology for studying wildfires}

The wildfire topic was built using all variations including hashtags, capitalization differences, and hyphenations of common words used to describe largescale fires including: wildfire, brushfire, grassfire, desert fire, hill fire, vegetation fire, and peat fire. All include and exclude terms for the fire topic are available in Appendix 1. Exclusions included online video games where parts of the fictitious world (often referred to as "map") may be on fire, and ideas on how to conquer these areas are often discussed in gaming chatrooms, blogs, etc.

Wildfires are named for the area in which they start and can be named after things such as a nearby lake, road, landmark, or town (Morning Edition 2015). Due to this naming structure, the names of the actual fires including variations and hashtags were included 
in the creation of the topic. Fires studied were the Mendocino Complex, Carr, Woolsey, and Camp fires. Individual searches for each fire included the fire name and associated hashtags. To compare the reaction of those who live in areas prone to wildfires two geographies were created: fire-prone states, and non-fire-prone states. Fire-prone states were determined using the insurance information institutes' (III) lists of fire-prone states by household and percent of household from 2013, 2015, and 2017 (III 2018). Fire states included California, Texas, Colorado, Arizona, Idaho, Washington, Oklahoma, Oregon, Utah, Montana, New Mexico, Wyoming, Nevada. Non-fire-prone states included all US states excluding the fire-prone states.

To evaluate the posts/news/blogs of those directly affected by the fire, geographies were parameterized for each fire's affected area. Individual details regarding the fires, including regions affected and dates, were collected from different sources. Information regarding the Mendocino Complex and Carr fires was sourced from the California government fire incident information website (Cal Fire 2018). Information regarding the Woolsey fire (CBSb 2018; Hamilton et al. 2018), Camp fire (Dowd 2018; CBSb 2018), and additional information regarding the Carr fire (Sanchez 2018) were sourced from news sites. The affected areas of the fires were more difficult to establish when compared to the hurricanes. Many of the counties that burned were located within national parks or sparsely populated areas. All large cities within the affected county for each fire were individually included within each individual fire's affected area geography. To capture the less inhabited areas, a geofence was placed around the general area of the affected county(s) for each fire. The geofence allows a shape to be drawn directly on a map of the USA, and only posts from the geofenced area are included (Appendix 3). The use of named larger cities and geofence were intended to facilitate capturing all potentially affected people for each individual fire. For example, the Camp fire affected area included geographies were Magalia California, Chico California, Chico-Redding California, Paradise California, Oroville California, Gridley California, and a geofence was drawn around the general area of Butte County, California (Appendix 3).

Unlike hurricanes, there is no standard or expected warning period or watching period for the development of individual/new named fires. However, it was hypothesized that posts would differ during and after each wildfire. Two time periods were established for each fire, during and after. The period during the fire was established as the time between when the fire started and containment. The time period after was defined as the day after containment plus 60 days. For example, the time period during the Carr fire was defined as July 23, 2018-August 31, 2018, and the time period after was defined as September 1, 2018-October 31, 2018. The time periods for each fire are available in Table 1. All search parameters employed for searching individual fires are available in Appendix 3.

\section{Results}

The percentages of females and males posting on social media regarding natural disasters are fairly equivalent (Table 2). Relatively high percentages of posters were 55-65 of age. There were more posts regarding hurricanes when considering the entire USA compared to the number of posts regarding fires. More posts about hurricanes came from hurricane states than non-hurricane states, while the opposite was true for fires in which more nonfire state posts were found. 


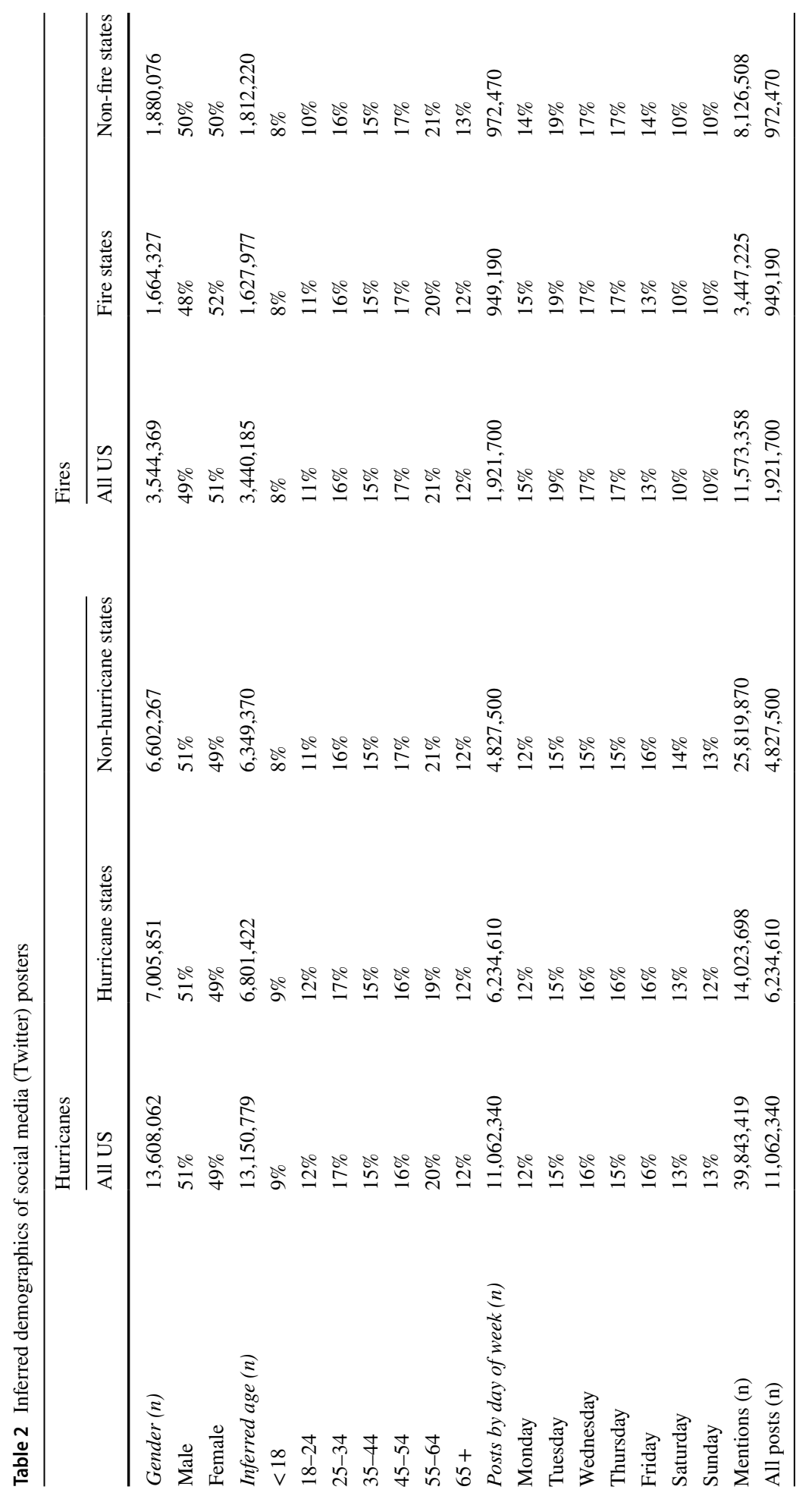




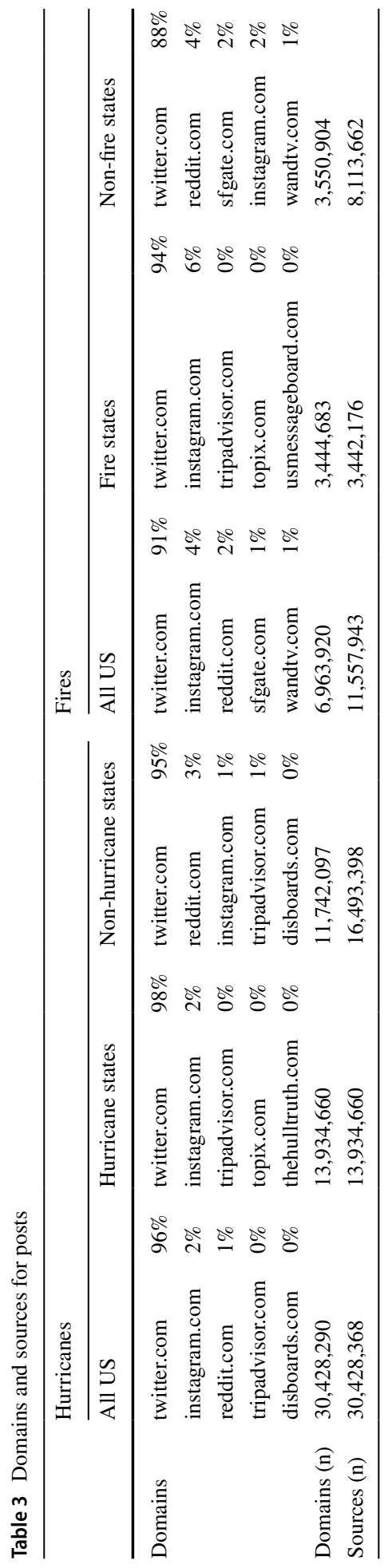


Table 4 Top 25 Terms in hurricanes search, by geography

\begin{tabular}{|c|c|c|c|c|c|}
\hline \multicolumn{2}{|l|}{ All US } & \multicolumn{2}{|l|}{ Hurricane states } & \multicolumn{2}{|l|}{ Non-hurricane states } \\
\hline $\mathrm{n}$ & $30,428,076$ & $\mathrm{n}$ & $13,934,660$ & $\mathrm{n}$ & $16,493,378$ \\
\hline hurricane Harvey & $3,798,592$ & Hurricane Harvey & $1,594,485$ & storm & $2,321,052$ \\
\hline Puerto Rico & $3,416,421$ & Hurricane Irma & $1,371,672$ & Hurricane Harvey & $2,204,141$ \\
\hline storm & $3,402,370$ & Puerto Rico & $1,286,202$ & Puerto Rico & $2,130,316$ \\
\hline Hurricane Irma & $3,085,931$ & Florida & $1,207,580$ & Trump & $1,904,768$ \\
\hline Florida & $3,050,337$ & Trump & $1,093,270$ & Florida & $1,842,741$ \\
\hline Trump & $2,998,020$ & storm & $1,081,239$ & Hurricane Irma & $1,714,259$ \\
\hline Hurricane Maria & $2,680,143$ & Hurricane Maria & $1,018,740$ & Hurricane Maria & $1,661,509$ \\
\hline help & $2,544,383$ & help & 942,902 & help & $1,601,460$ \\
\hline hit & $2,040,344$ & Texas & 660,186 & hit & $1,387,901$ \\
\hline Texas & $1,850,785$ & hit & 652,450 & home & $1,103,193$ \\
\hline Hurricane Matthew & $1,480,662$ & Hurricane Florence & 630,323 & state & $1,070,531$ \\
\hline home & $1,453,731$ & Hurricane Matthew & 603,381 & damages & 989,835 \\
\hline Hurricane Florence & $1,429,756$ & \#Irma & 493,150 & island & 906,368 \\
\hline state & $1,391,836$ & power & 361,854 & left & 892,447 \\
\hline Powered & $1,229,240$ & hurricane season & 361,009 & Hurricane Matthew & 877,282 \\
\hline left & $1,201,381$ & @ realDonaldTrump & 360,320 & power & 867,187 \\
\hline island & $1,182,165$ & donate & 360,096 & Hurricane Florence & 799,463 \\
\hline Updated & $1,060,341$ & BREAKING & 332,346 & reported & 742,299 \\
\hline landfall & 998,714 & Hurricane Michael & 332,037 & working & 706,286 \\
\hline shows & 966,255 & landfall & 319,240 & caused & 702,326 \\
\hline caused & 888,580 & affected & 291,956 & Updated & 688,443 \\
\hline \#Irma & 875,230 & safe & 289,533 & shows & 679,463 \\
\hline @ realDonaldTrump & 827,022 & stay & 262,507 & landfall & 679,430 \\
\hline $\mathrm{mph}$ & 756,385 & hurricane victims & 246,552 & $\mathrm{mph}$ & 541,042 \\
\hline Hurricane Michael & 723,568 & \#Harvey & 225,425 & $\begin{array}{l}\text { National Hurricane } \\
\text { Center }\end{array}$ & 422,655 \\
\hline
\end{tabular}

Twitter.com encompassed the highest percentage of posts by far for both disasters and all geographies (Table 3). Compared to hurricane posts, there were slightly higher percentages of posts from Instagram.com for both fire and non-fire states. For all regions studied, the top 4 terms included references to hurricane Harvey, Puerto Rico, and Hurricane Irma. For all area categories, the term help appeared in the top 10 terms, but unique to hurricane states, the terms donate, and hurricane victims also appeared (Table 4). Unique to fires, the term firefighters appeared in the top 5 terms for all three geographies (Table 5). Also unique to fire states were words that likely described individual situations such as safe, fleeing, and lost although evacuate did appear as a top term in both wildfire and nonwildfire geographies. Climate change only appeared as a top term for US and wildfire state geographies for wildfires.

For the five hurricanes included in this analysis, there were more mentions after the hurricane than before (Table 6). For hurricanes, the total number of mentions for direct impact states was 2,246,566, for hurricane states 4,346,500, and for non-hurricane states $9,226,759$. For direct impact states, hurricane states, and non-hurricane states mentions before the hurricanes accounted for $99.93 \%, 99.28 \%$, and $99.30 \%$ of posts, respectively. For 
Table 5 Top 25 Terms in wildfires search, by geography

\begin{tabular}{|c|c|c|c|c|c|}
\hline \multicolumn{2}{|l|}{ All US } & \multicolumn{2}{|l|}{ Wildfire states } & \multicolumn{2}{|l|}{ Non-wildfire states } \\
\hline $\mathrm{n}$ & $8,535,219$ & $\mathrm{n}$ & $3,413,636$ & $\mathrm{n}$ & $5,121,629$ \\
\hline homes & $1,056,816$ & California wildfires & 326,385 & homes & 778,768 \\
\hline California wildfires & 961,057 & home & 251,439 & burn & 664,672 \\
\hline burns & 898,853 & help & 249,151 & California wildfires & 634,691 \\
\hline Firefighters & 796,758 & acres & 238,488 & state & 577,398 \\
\hline area & 734,567 & firefighters & 229,926 & Firefighters & 566,839 \\
\hline helped & 732,635 & burned & 222,823 & area & 545,705 \\
\hline spread & 638,229 & areas & 190,263 & helped & 483,343 \\
\hline acres & 618,474 & smoke & 176,233 & spread & 478,177 \\
\hline smoke & 490,436 & update & 163,058 & destroyed & 390,856 \\
\hline Updated & 487,027 & spread & 160,063 & acres & 379,987 \\
\hline destroying & 470,135 & evacuate & 124,061 & official & 366,568 \\
\hline evacuated & 412,548 & lost & 121,103 & AP & 356,789 \\
\hline report & 409,480 & fighting & 105,429 & blaze & 346,942 \\
\hline blazes & 395,562 & affected & 101,167 & report & 329,532 \\
\hline killed & 390,509 & working & 97,047 & killed & 324,452 \\
\hline working & 385,039 & battling & 94,052 & Updated & 323,639 \\
\hline $\mathrm{AP}$ & 385,021 & contained & 92,557 & smoke & 314,206 \\
\hline started & 384,096 & Southern California & 81,139 & started & 305,511 \\
\hline battling & 378,468 & safe & 77,949 & work & 283,654 \\
\hline fighting & 367,835 & climate change & 77,768 & evacuate & 279,552 \\
\hline flames & 335,895 & using & 72,178 & battle & 275,782 \\
\hline contained & 330,736 & @ realDonaldTrump & 64,181 & flames & 272,980 \\
\hline Southern California & 313,679 & flames & 62,922 & residents & 271,109 \\
\hline cause & 306,700 & \#california & 56,752 & fighting & 262,411 \\
\hline climate change & 268,529 & fleeing & 50,431 & contained & 238,180 \\
\hline
\end{tabular}

all three regions studied, the percentages of mentions occurring before were statistically different from the percentage of mentions occurring after using the test of proportions.

There were more mentions during the fires and fewer after for all fires studied (Table 6). It is difficult to compare across the hurricanes and fires because each has a unique timeframe, with some lasting much longer than others. To visualize the volume of mentions, Figs. 1, 2, 3, 4, 5, 6, 7, 8, and 9 present the number of mentions weekly for the duration of the natural disaster. For all hurricanes studied, the number of posts was the highest for all geographic categories, the week of landfall and the following week, with the number of posts quickly diminishing. Hurricane Harvey had the highest number of mentions in the USA when compared to the other hurricanes. Interestingly, despite the horrible devastation caused by hurricane Maria, the peak number of mentions in the USA was less than 600,000 (Fig. 4) almost 5 times less than the peak number of mentions for hurricane Harvey (Fig. 2).

The Camp fire had the largest number of mentions, when compared to all other fires (Fig. 6). Conversely, the Mendocino complex fire had the highest number of mentions (Fig. 8). For all fires, the largest number of mentions typically occurred weeks before the 
Table 6 Mentions before and after natural disasters
Mentions

Hurricane Florence

$2,138,477^{\mathrm{a}}$

$16 \%^{\mathrm{b}}$

Direct impact area

Before

After

$1,986,969$

Hurricane states

Before

After

679,057

Non-hurricane states

Before

After

$1,430,753$

Hurricane Harvey

$4,266,391$

$31 \%$

Direct impact area

Before

After

Hurricane states

Before

After

Non-hurricane states

Before

After

$2,821,402$

Hurricane Irma

$4,413,792$

$32 \%$

Direct impact area

Before

After

Hurricane states

Before

After

Non-hurricane states

Before

After

$2,969,411$

Hurricane Maria

$1,589,297$

$12 \%$

Direct impact area

Before

After

Hurricane states

Before

After

Non-hurricane states

Before

3154 
Table 6 (continued)

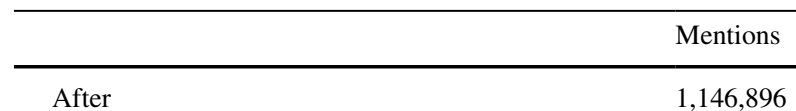

Hurricane Michael

$1,165,302$

$9 \%$

Direct impact area

Before

After

Hurricane states

Before

After

371,166

Non-hurricane states

Before

After

793,559

Camp Fire

925,751

$55 \%$

Direct impact area

During

7048

After

Fire states

During

332,268

After

Non-fire states

During

498,912

After

61,134

Carr Fire

294,966

$18 \%$

Direct impact area

During

After

Fire states

During

After

Non-fire states

During

188,295

After

Mendocino Fire

44,573

$3 \%$

Direct impact area

During

After

Fire states

During

11,596

After 
Table 6 (continued)

\begin{tabular}{lr}
\hline & Mentions \\
\hline During & 29,814 \\
After & 2970 \\
Woolsey Fire & \\
409,905 & \\
$24 \%$ & \\
Direct impact area & 18,147 \\
During & 2610 \\
After & \\
Fire states & 172,542 \\
During & 13,883 \\
After & \\
Non-fire states & 206,506 \\
During & 16,974 \\
After & \\
\hline
\end{tabular}

${ }^{a}$ Total number of mentions for the disaster for the period studied

${ }^{\mathrm{b}}$ Percentage of total mentions across all hurricanes or fires

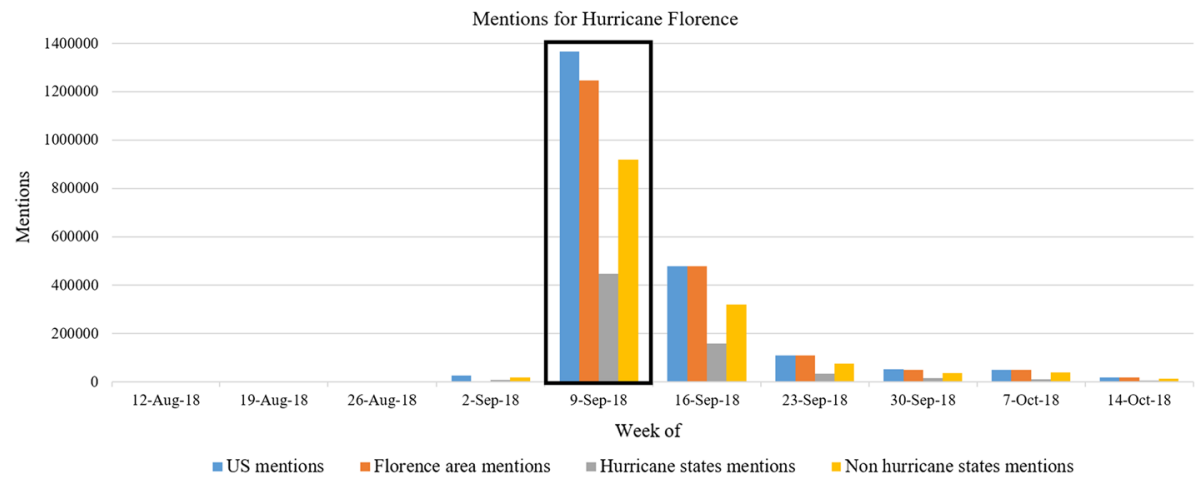

Fig. 1 Mentions for Hurricane Florence by geographic area. Note Box indicates week of midway point

end of the fire. Mentions increased at the beginning of fires, and then decreased. Total mentions occurring during the fires for direct impact states were 32,468 , for fire states 662,608 , and for non-fire states 1,012,587. For direct impact states, the percentage of mentions occurring during the fires accounted for $88.35 \%$ of mentions. For fires states, mentions during fires accounted for $92.33 \%$, and for non-fire states $91.20 \%$. Using the test of proportions, it was determined that the percentage of mentions for all regions occurring during the fires was statistically different than the percentage occurring after the fires. The Mendocino Complex fire took almost 3 months to put-out, and by the end of the fire, very few people were posting about it on social media.

FEMA and Red Cross aid as well as reported economic impact for the hurricanes studied are available in Table 7. Using the test of proportions, the percentage of FEMA assistance application, FEMA aid, Red Cross donations, economic impact, and mentions were statistically compared between the hurricanes studied. Irma had the highest percentage of 


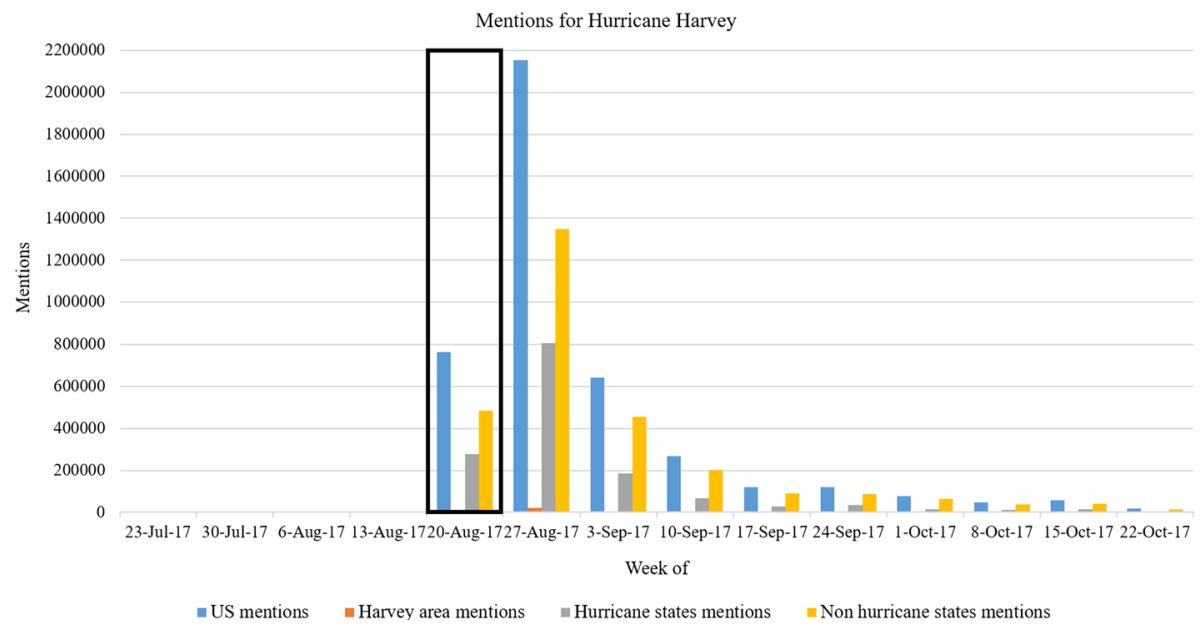

Fig. 2 Mentions for Hurricane Harvey by geographic area. Note Box indicates week of midway point

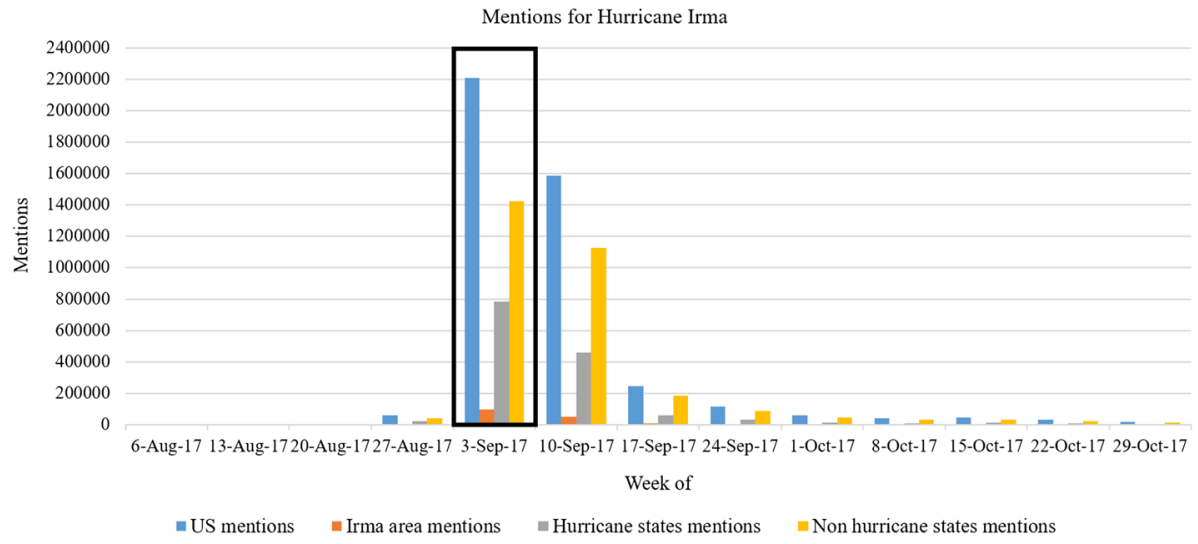

Fig. 3 Mentions for Hurricane Irma by geographic area. Note Box indicates week of midway point

FEMA assistance applications (46\%), followed by Maria (28\%), and Harvey (22\%). Florence and Michael tied for lowest percentage of applications (2\%). For total FEMA aid, Maria had the highest percentage of aid dollars (58\%), followed by Harvey (21\%), and Irma (14\%). Again, Florence and Michael tied for last at 3\% each. Hurricane Harvey had the highest percentage of Red Cross donations (68\%) followed by Irma (12\%). Hurricane Maria and Florence tied for 3rd with 9\%, and hurricane Michael had the lowest percentage (5\%). Harvey had the highest economic impact (40\%), followed by Maria (29\%), and Irma (16\%). Michael and Florence were tied for last at $8 \%$. Hurricanes Irma (33\%) and Harvey (31\%) tied for first in terms of highest percentage of mentions (Table 6). Florence was second (16\%), followed by Maria (12\%) and Michael (9\%). 


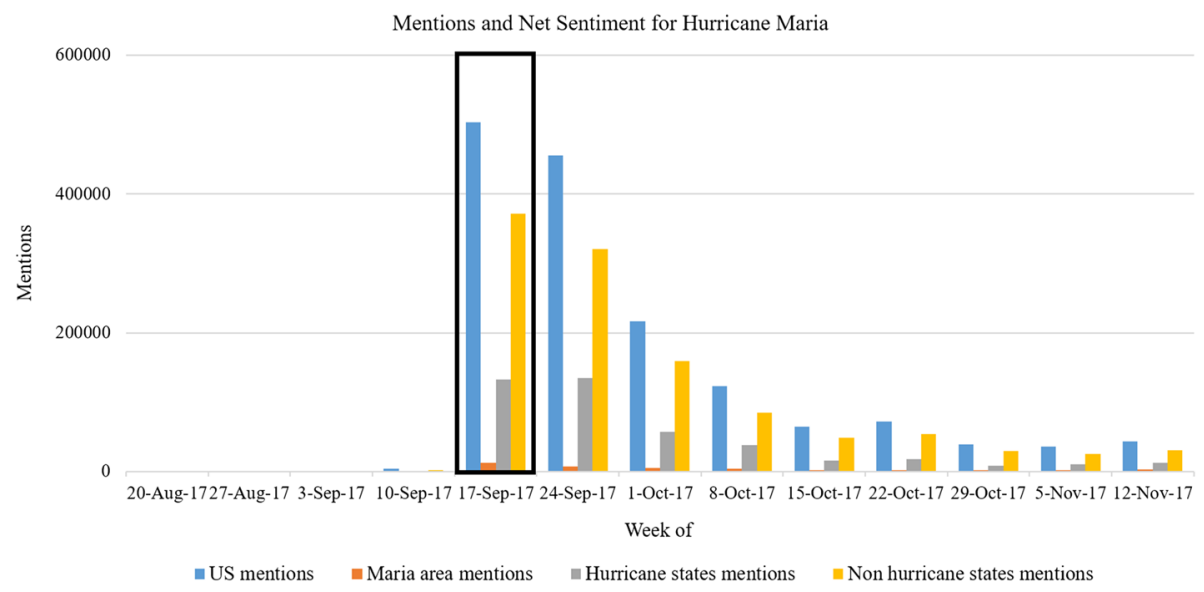

Fig. 4 Mentions for Hurricane Maria by geographic area. Note Box indicates week of midway point

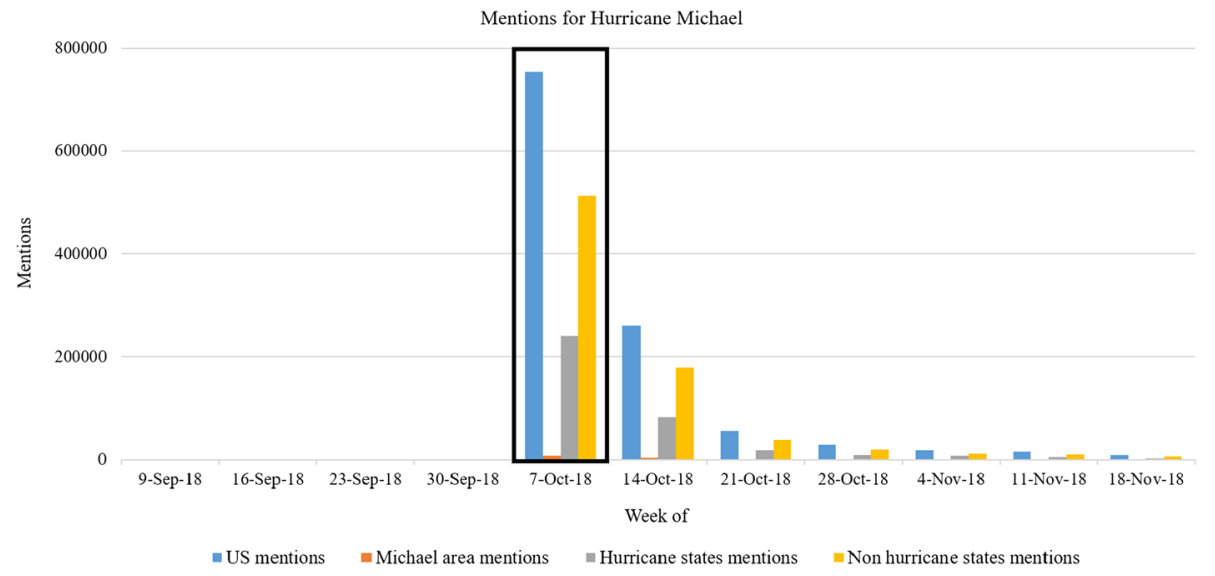

Fig. 5 Mentions for Hurricane Michael by geographic area. Note Box indicates week of midway point

\section{Discussion}

In a 2015 survey, Perrin (2015) found that roughly equal percentages of men $(62 \%)$ and women $(68 \%)$ were using social media. Natural disasters impact geographic areas independent of gender, so it is unsurprising that such events would be of equal concern/interest to both men and women. Although young adults between 18 and 29 years old are more likely to be social media users, $35 \%$ of people 65 and older are using social media, which has more than tripled since 2005 (Perin 2015). Looking specifically at Twitter, for which this study has demographic information, in a 2012 study $27 \%$ of those $18-29$ used Twitter while only $2 \%$ of those 65 and older used Twitter (Duggan and Brenner 2013). The increased interest in participating in natural disaster discussion on social media of older posters may be the result of making disaster plan decisions for their families, or being more likely to have property that could be impacted by a disaster. 


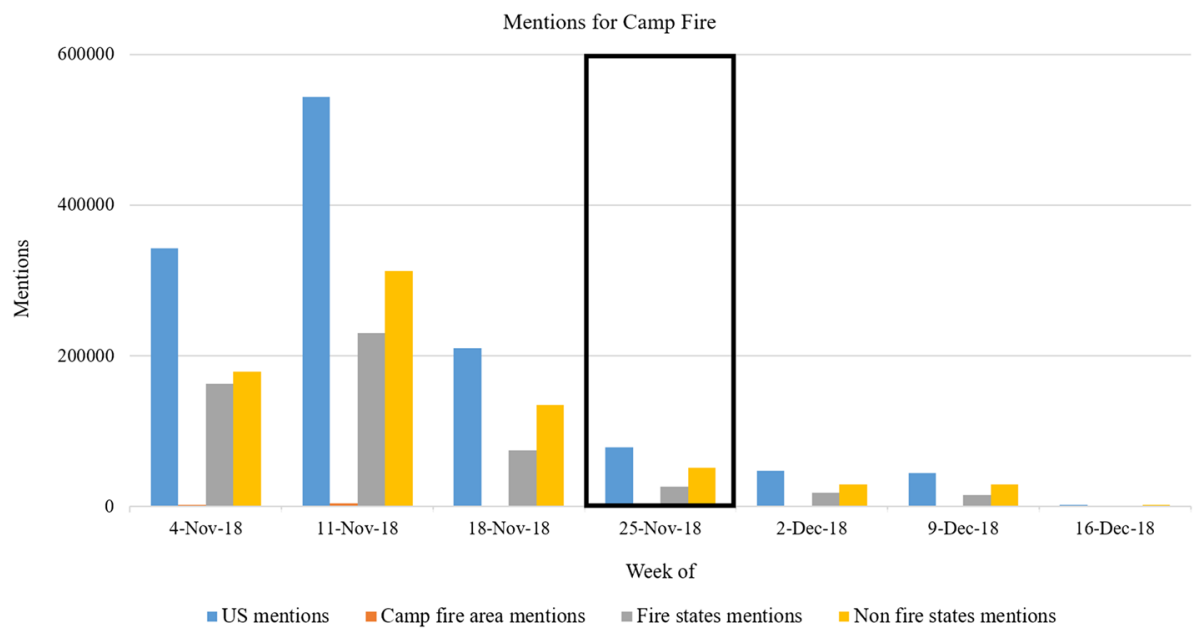

Fig. 6 Mentions for Camp Fire by geographic area. Note Box indicates week fire was declared over

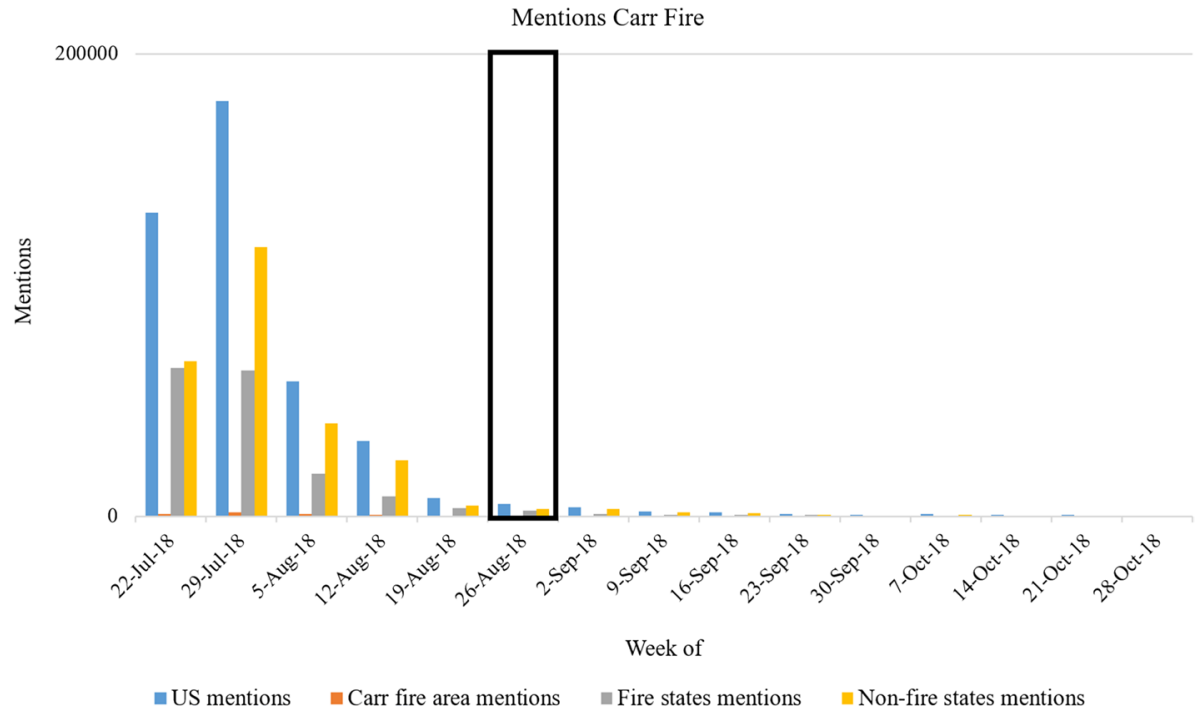

Fig. 7 Mentions for Carr Fire by geographic area. Note Box indicates week fire was declared over

Given the destruction related to hurricane Harvey and the destruction Hurricane Irma caused in Puerto Rico (Halverson 2018), top terms for hurricanes related to these storms were unsurprising. Terms related to helping and providing relief were common in the hurricane states. Anecdotally, hurricane-impacted zones, and in particular those which faced devastation in recent memory are featured as providing relief for newly impacted zones. For example, southern states' residents aided others along the Gulf Coast in recent years in the aftermath of hurricanes Harvey, Irma, and Florence in Texas, Central Florida, and North Carolina. For example, the Cajun navy is a volunteer relief and rescue group that uses personal boats to aid in the relief and rescue of those in Louisiana and surrounding 


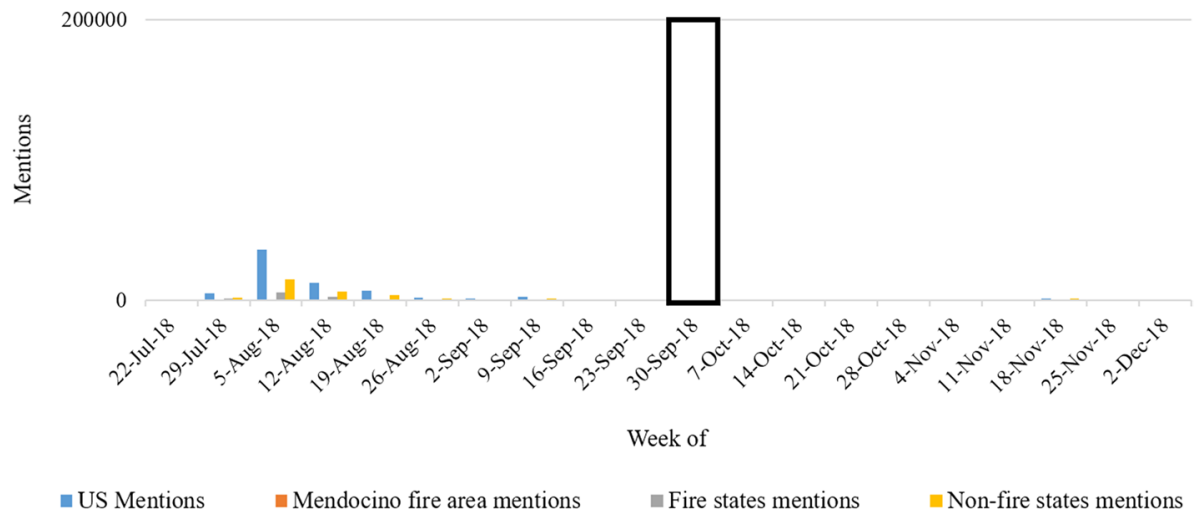

Fig. 8 Mentions for Mendocino Fire by geographic area. Note Box indicates week fire was declared over

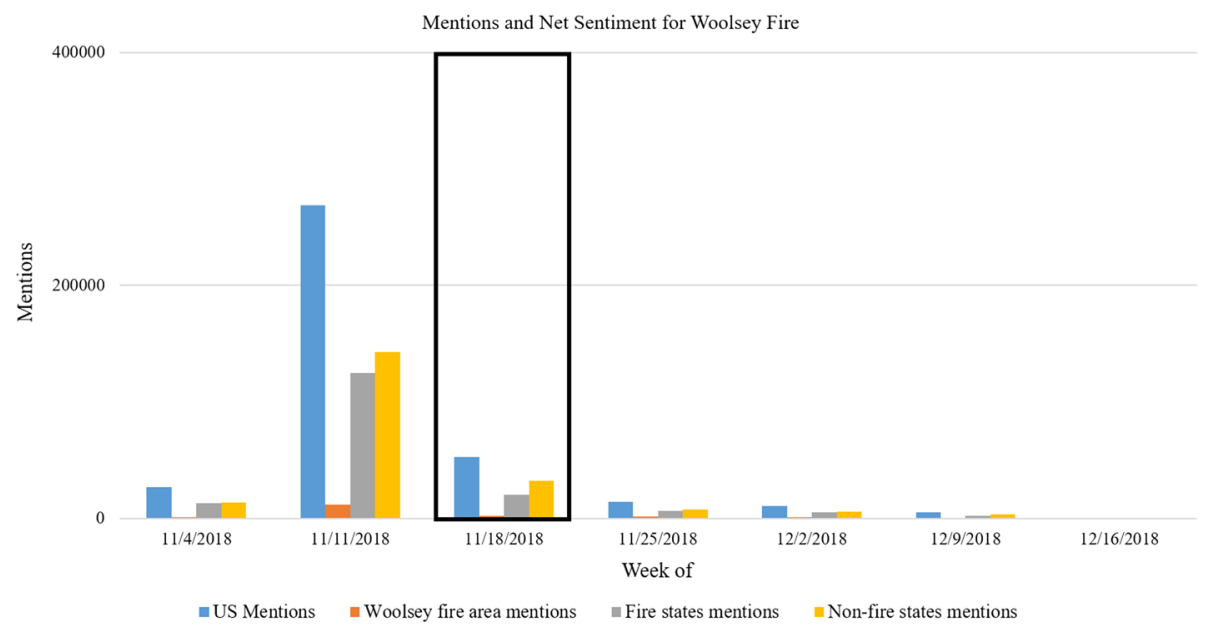

Fig. 9 Mentions for Woolsey Fire by geographic area. Note Box indicates week fire was declared over

states (Cajun Navy 2019). The Cajun Navy self-describes as, "Rescue and relief is our way of sharing our South Louisiana cultural tradition (of neighbors helping neighbors) with people in need across the United States" (Cajun Navy 2019).

There are many possible explanations for the increased number of posts regarding hurricanes in comparison with fires found in this research. The impacts, financially, socially, and culturally, of natural disasters are partially driven by geographic locale of the disaster. The US coasts are highly populated (Wilson and Fischetti 2010), which may result in higher numbers of people being directly impacted by hurricanes than fires. This population factor may influence the number of social media posts, and possibly the content of posts regarding hurricanes in comparison with fires. Hurricane Harvey had the highest percentage of Red Cross donations, and was tied with Irma for highest percentage of mentions. The high population of the Houston area, and severity of the storm resulted in high economic impact. It may be assumed that denser populations and greater disaster severity 


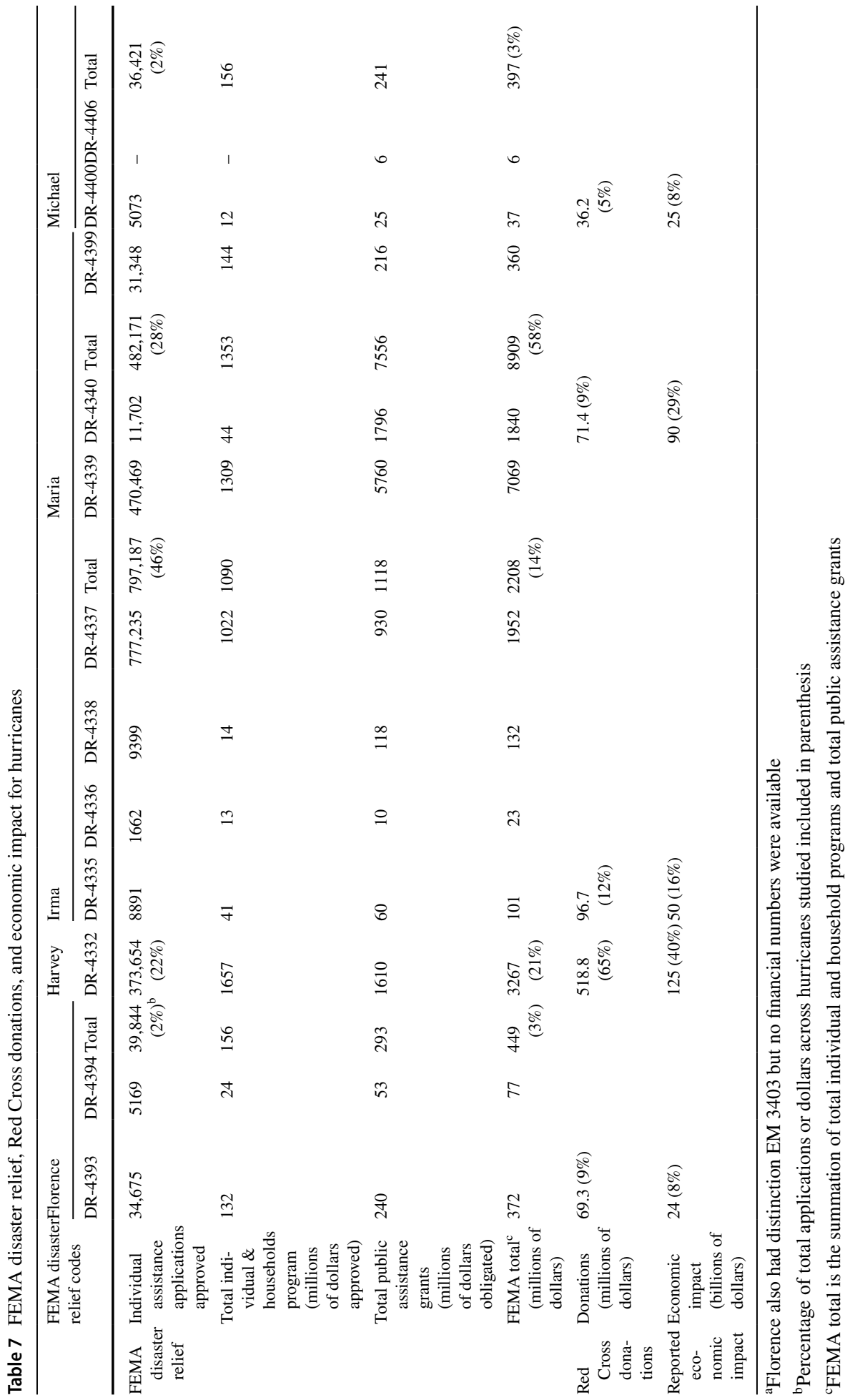


would result in a higher storm impact and media attention. However, it would be difficult to measure the individual impact of any one variable, given the population clusters along the shore, and the fact that hurricanes impact the coast. Conversely, although hurricane Maria ranked second in terms of economic impact, it was third in terms of donations, and $3^{\text {rd }}$ in terms of social media mentions, giving credence to the idea there are other factors involved beyond the amount of devastation.

Posts peaked in volume the week of landfall and quickly diminished. Previously, Martin et al. (2017) found that peak Twitter response happened leading up to hurricane Mathew and quickly decreased after its passage. Hurricane Harvey and Irma had the largest percentage of total mentions, even though other hurricanes including Maria were also destructive. This is likely due to the amount of destruction caused by hurricane Harvey. Kempton (2019) analyzed Newspaper coverage of hurricanes Harvey and Maria and found that news coverage may be biased by geographic, social, and racial inequalities. Hurricane Maria was framed with more political intent in newspapers and hurricane Harvey was more often framed as human interest (Kempton 2019). More research would be needed to determine the prevalence of such biases in social media coverage. Additionally, Harvey, Irma, and Maria all hit roughly within a 1-month period which may have resulted in compassion fatigue for those not directly impacted.

Monetary aid decreased from Harvey to Maria which did not align with storm severity or prevention (Conway 2019). Reasons for staggered decreases in donations could have been the result of donor fatigue, difficulty in accessing unfamiliar geographic areas such as Puerto Rico and the US Virgin Islands, and potential racial bias or donor perception (Conway 2019). "Offering 'thoughts and prayers' has become a standard response from both US policy makers and the public to major catastrophes-including hurricanes, wildfires, mass shootings, and disease outbreaks." (Thunstrom and Noy 2019). A survey conducted by Taylor et al. (2012) reported that people undergoing a disaster feel more supported and optimistic about their situation when social media were extensively involved, supporting the argument. While social media and peer-to-peer communication may facilitate the outpouring or expression of concern, including offering up thoughts and/or prayers, recent work has been critical in the sense that nonreligious people have been found to negatively value such gestures from Christians and are indifferent to receiving them from other nonreligious people (Thunstrom and Noy 2019). More importantly, one might argue that gestures meant in goodwill could actually replace other communications and/or other aid. In short, regardless of the specific value of a thought and/or prayer to an individual person or group of people, in total are those offering such gestures doing so in place of or alongside other assistance.

Wildfires, particularly in the Western US are, in contrast to hurricanes, more local in their impacts, yet terrifying due to their destructive unpredictable nature. Oftentimes wildfires, particularly in the western states of the USA occur in relatively unpopulated areas; however, as populations grow in these areas, especially California, the impact could become greater (Schoen and McDonald 2019). The recent number of lives lost in large, fast-moving fires through residential and more populated zones along with the fires occurring outside of the traditional wildfire season, has driven attention to the devastation that wildfires cause (Boghani 2019). The Camp fire was the deadliest wildfire in California's history with 85 people losing their lives (Boghani 2019). Over 18,800 structures were destroyed, with the vast majority of them being residences (Boghani 2019). The differences between the populations affected by hurricanes and fires may in part explain why higher numbers of hurricane states posted about hurricane disasters than non-states, while 
the reverse is true for fires. Despite not residing in a fire state, many people were still joining in the conversation regarding the fires included in this analysis.

Unlike hurricanes, fire content included fairly high Instagram usage. This difference, may be in part due to the large impact of recent wildfires in California. Despite all of the positive uses of social media during a natural disaster, the phenomenon of "keyword squatting," using keywords or hashtags related to an event to promote unrelated products, became common during the California wildfires (Ma 2018). Influencers were using previous pictures of locations in California or posting things like wine Wednesday while using the tag \#californiafires and promoting items (Ma 2018). Although there are some people using social media for personal gain in light of natural disasters, the ability to help people and disseminate information likely outweighs this downside.

There is no way to put-out or stop a hurricane; however, firefighters can help stop or mitigate damages related to wildfires, and firefighters appeared as a top term related to fires. The US forest service employs approximately 10,000 wildland firefighters with specific roles and training (USDA 2020). Due to chronic understaffing and the longer fire season, firefighters are working overtime, and some firefighters say working 32 days straight is the new normal (Morris 2018). Although public concern for firefighters as seen through social media may rise during natural disasters, the conversations regarding solutions to the understaffing and overworking problem likely need to occur during non-disaster times.

Despite being the largest fire in California history (Solomon 2018), the Mendocino Complex fire had the lowest number of peak mentions (Fig. 8). However, the Camp fire was one of the deadliest and costliest fires of all time (Solomon 2018). This point demonstrates that many measures of natural disasters are needed to portray the entire impact on communities, natural places, and the economy. A key finding across all fires was that the chatter related to fires died out long before the fires themselves. This pattern may cause issues for those seeking recovery help, as the chatter on social media has died down by the time recovery efforts are underway. Words related to fleeing appeared only in wildfire states. Monitoring language such as this can help rescue and aid organization know where help is needed. Despite potential links to climate change and increased hurricane activity (Halverson 2018), the word climate change only appeared in relation to wildfires. Observed warming and drying have resulted in significant increases in fire-season fuel aridity, half of which Abatzoglou et al. (2016) have attributed to human-caused climate change.

In talking about the 2017 hurricane season, Halverson (2018) states and answers a key question, "How much did climate change factor into the season's destructiveness? The densely populated targets of Harvey, Irma, and Maria undoubtedly played the largest factor of economic and life losses. And while no single storm is ever caused by global warming, aggregate, long-term changes in the storm environment (both oceanic and atmospheric) might be creating a statistical uptrend in factors such as storm frequency, size, wind intensity, geographic coverage, storm duration, and rainfall." In short, the location of natural disasters has a clear and obvious impact on the amount of damage, both economically and in loss of life. But, the uptrend in total numbers of hurricanes and fires also points toward the need for increased preparation and research on risk mitigation and disaster communication regardless of the causes, or the quantity of occurrences. 


\section{Conclusion}

Online media responses to natural disasters vary based on the type of disaster, geography, population impacted, and severity of damage. Social media mentions related to hurricanes outnumbered fires, which mostly can be attributed to higher population densities in coastal areas (Wilson \& Fischetti 2010). Analysis of social media terms related to natural disasters can be helpful to those monitoring and disseminating aid; however, there are many potential pitfalls to be aware of. There are those who prey on the rise in natural disaster social media content to increase promotion for unrelated products. Additionally, content may not be directly related to the devastation of an event, as compassion fatigue may play a role with increasing frequencies of natural disasters. Future research can further analyze the potential effects of compassion fatigue, as well as demographics associated with those impacted and social media content. There is a mismatch between the time periods that people post about natural disasters on social media and the times when aid is needed to rebuild. Mentions fall rapidly after the event for hurricanes, and long before fires are officially put-out. This may leave populations without help and support when struggling with the rebuilding process after the online media attention dissipates.

\section{Appendix 1: Primary search terms}

\section{Hurricane Primary Terms}

Hurricane, \#Hurricane, hurricane, \#hurricane.

\section{Hurricane Exclude terms}

penis, porn, Pat O'Brien, Pat O'Brien's, wallbangers, lottery, Thanksgiving in the Park, @mcp_polm, hurricane pike, Galaxy Note 8, IPhone, Apple, iphone, cowlick, my little hurricane, rain dance, hurricane swing, gut punches, limousine, leafsnet, football, player, hockey, baseball, life is like a hurricane, rock you like a hurricane, shithuts, Scorpions, spitfire, swirl inside you, gay ass, atsushi, stormrazor, Dota, Dota2, Dota 2, pissing in the wind, hard shiny, void, Oscars, Academy Awards, asshole, AKR Princess, Commander, Equestria, Monsters, Meaty, bowl, bowl game, Cotton Bowl, Orange Bowl, Heroes of the Storm, Heros of the Storm, @tnbuckeye44, xmen, X-men, Magento, Marvel, Marvel Comics, League of Legends, Elder Scrolls, Skyrim, NHL, hat trick, hat-trick, Martinook, @ golf_mansion, @lamaritzan, WillHaftawaite, Detroit, AIDS, zombie, zombies, Fortnite, Jim Weltzin, basketball, Gregory Helms, WWE, pokemon, hoothoot, flying type, Mr4DoubleO, rugby, Huntly, Nightingale, grammy, RIAA, music, StateOfTheU, StateOfTheU.com, @evanjm02, cyyandye, Possible_Indeed, SevenSport, kiosport, @LoriPlanken, Tulsa, TU, Tulsa University, @SMarcLeger_MBA, Thor Industries, Winnebago.

\section{Hurricane Geographies}

USA.

\section{Wildfire primary terms}


wildfire, wild-fire, \#wildfire, Wildfire, \#Wildfire, brushfire, Brush Fire, Wild Fire, wild fire, brush fire, brush-fire, Brushfire, \#brushfire, \#Brushfire, grassfire, grass-fire, Grassfire, grass fire, Grass Fire, \#Grassfire, \#grassfire, desert fire, Desert Fire, desertfire, Desertfire, \#desertfire, \#Desertfire, desert-fire, Hill Fire, Hillfire, hill fire, hill-fire, \#hillfire, \#Hillfire, hillfire, vegetation fire, Vegetation Fire, vegetationfire, Vegetationfire, vegetation-fire, \#vegetationfire, peat fire, peatfire, peat-fire, Peat Fire, \#Peatfire, \#peatfire, Peatfire, Camp Fire, \#Campfire, Woolsey Fire, \#Woolseyfire, Carr fire, \#Carrfire, Mendocino Complex Fire, \#Mendocinocomplexfire, Fergusen Fire, \#Fergusenfire, Thomas Fire, \#Thomasfire, Tubbsfire, Lodegpole Complex Fire, \#Lodgepolecomplexfire, Lolo Peak Fire, \#Lolopeakfire, Anderson Creek Fire, \#Andersoncreekfire.

\section{Wildfire exclude terms}

penis, porn, @jaesyun_, @AssangeJohn, @carleigh1985, @Schmeltz79, @nessuhhx, @ BetteMidler, @RebeccaRage33, @ dicapriofdn, @CaliforCode, Fortnite, \#Fortnite, @Fortnite, Epic Game, EpicGames, @KurtSchlichter, @salianij, @ chicksaction, xxxtentacion, kaunis, cynycal, \#NetNeutrality, Kalanianaole, flooding, flash flooding, racist, nuclear, Doznotcomputer, SmackDown, El Greco, PSG, @ haydenblack, @ AndOneTech, TheKuMan717, @CoyoteWildfire, mini-Ice Age, Whoader95, Miocene, Pakistan.

\section{Wildfire Geographies}

USA.

\section{Wildfire Exclude domains}

Steamcommunity.com.

\section{Appendix 2: Individual hurricane search parameters}

\section{Florence-specific terms}

Include: Hurricane Florence, \#HurricaneFlorence, \#hurricaneflorence.

Florence before date range: August 11, 2018-September 10, 2018.

Florence after date range: September 11, 2018-November 10, 2018.

\section{Florence area}

Include geography: Wilmington, North Carolina.

\section{Florence non-area}

Exclude geography: Wilmington, North Carolina. 


\section{Michael-specific terms}

Include: Hurricane Michael, \#HurricaneMichael, \#hurricanemichael.

Michael before date range: September 13, 2018-October 13, 2018.

Michael after date range: October 14, 2018-December 13, 2018.

\section{Michael area}

Include geography: Tallahassee Thomasville metro area.

\section{Michael non-area}

Exclude geography: Tallahassee Thomasville metro area.

\section{Maria-specific terms}

Include term: Hurricane Maria, \#HurricaneMaria, \#hurricanemaria.

Maria before date range August 24, 2017-September 23, 2017.

Maria after date range September 24, 2017-November 23, 2017.

\section{Maria area}

Include geography: Puerto Rico.

\section{Maria non-area}

Exclude geography: Puerto Rico.

\section{Irma-specific terms}

Include term: Hurricane Irma, \#HurricaneIrma, \#hurricaneirma.

Irma before date range August 8, 2017-September 7, 2017.

Irma after date range September 8, 2017-November 7, 2017.

\section{Irma area}

Include geography: Miami-Ft. Lauderdale metro area.

\section{Irma non-area}

Exclude geography: Miami-Ft. Lauderdale metro area.

\section{Harvey-specific terms}


Include term: Hurricane Harvey, \#HurricaneHarvey, \#hurricaneharvey.

Harvey before date range July 25, 2017-August 24, 2017.

Harvey after date range August 25, 2017-October 24, 2017.

\section{Harvey area}

Include geography: Miami-Ft. Lauderdale metro area.

\section{Harvey non-area}

Exclude geography: Miami-Ft. Lauderdale metro area.

\section{Appendix 3: Individual wildfire search parameters}

\section{Camp fire-specific terms}

Include term: camp fire, \#campfire, \#CampFire.

Camp fire during date range: November 8, 2018-November 25, 2018.

Camp fire after date range: November 26, 2018-December 16, 2018.

Camp fire area *all available cities in Butte Co.

https://www.worldatlas.com/na/us/ca/c-butte-county-california.html.

Include geographies: Magalia California, Chico California, Chico-Redding California, Paradise California, Oroville California, Gridley California.

Geofence: Butte County.

Actual County: https://www.google.com/maps/place/Butte+County,+CA/@39.72208 $07,-122.1332831,9 \mathrm{z} / \mathrm{data}=! 4 \mathrm{~m} 5$ !3 m4! 1s0x809cd6015b7e73ab:0x856e3671 0c15f $993 ! 8 \mathrm{~m} 2 ! 3 \mathrm{~d} 39.6253952$ !4d-121.5370003. 


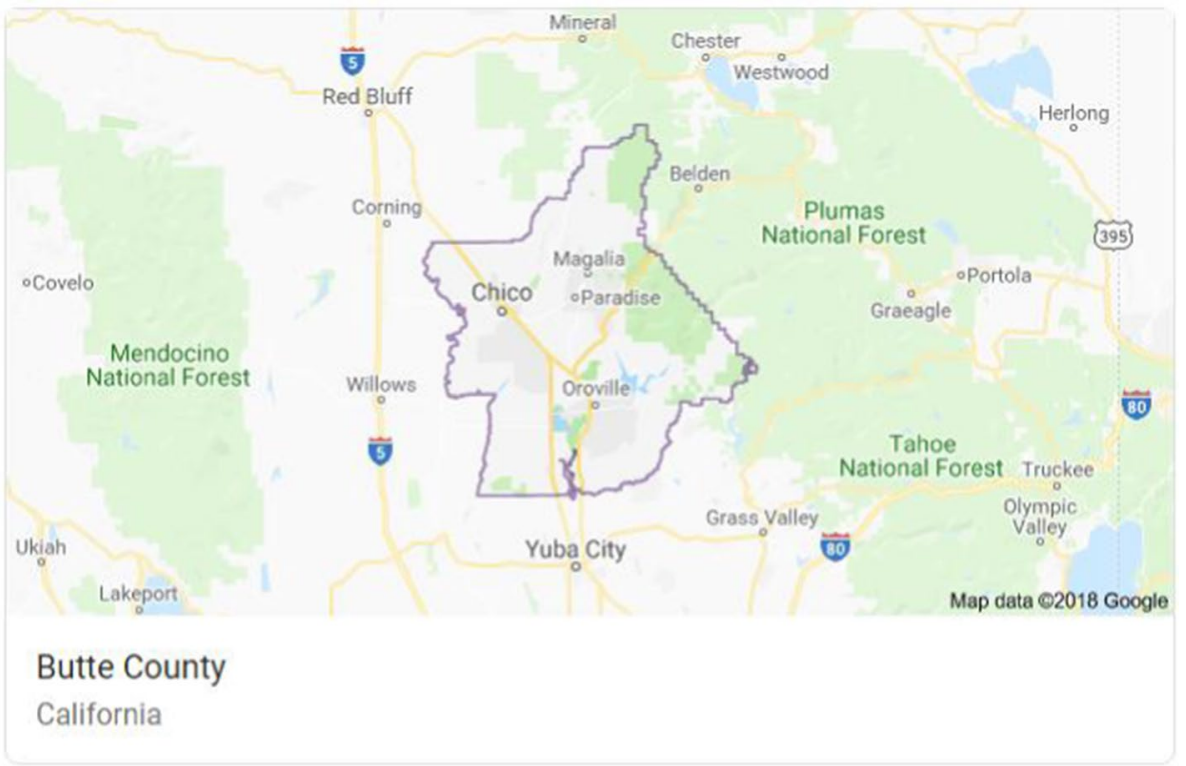

\section{Geofence area:}

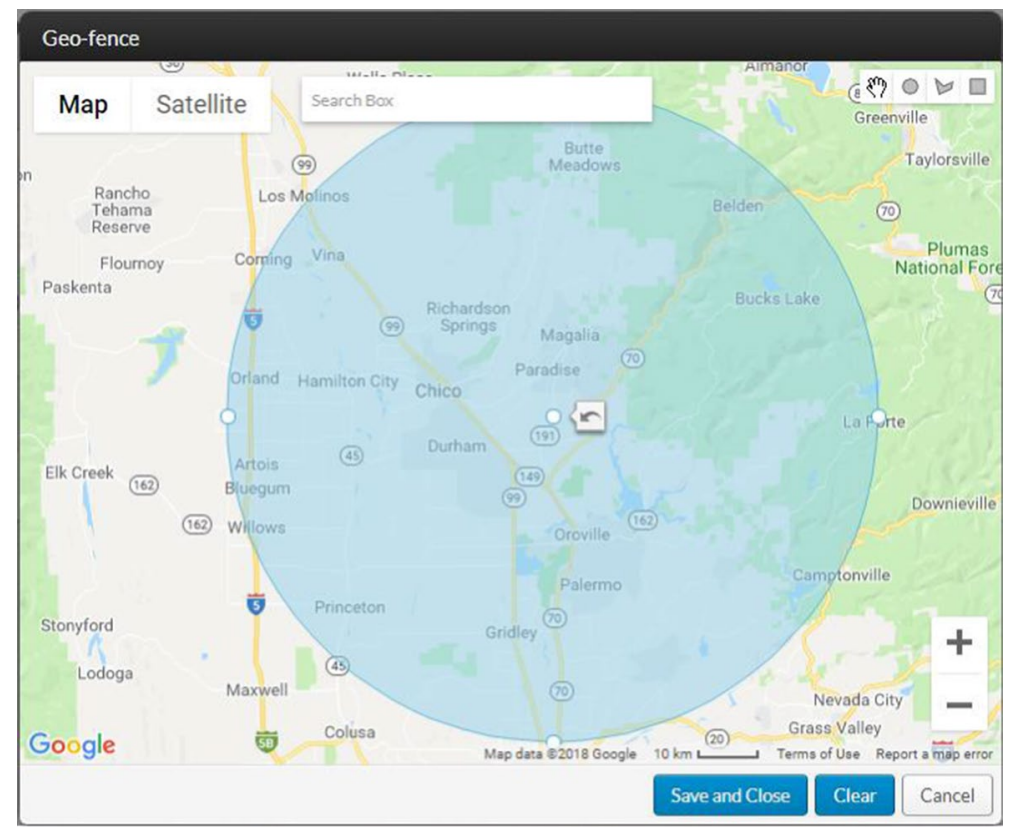




\section{Woolsey fire-specific terms}

Include term: Woolsey fire, \#WoolseyFire, \#woolseyfire.

Woolsey fire during date range: November 11, 2018-November 22, 2018.

Woolsey fire after date range: November 23, 2018-December 16, 2018.

Woolsey fire area *all available cities in Los Angeles County and Ventura County.

https://www.worldatlas.com/na/us/ca/c-los-angeles-county-california.html.

https://www.worldatlas.com/na/us/ca/c-ventura-county-california.html.

Include geographies: Lancaster, Santa Clarita, Thousand Oaks, Los Angeles-metro, Los Angeles, Long beach, Santa Ana, Glendale, Palmdale, Pomona, Torrance, Pasadena, El Monte, Downey, Inglewood, West Covina, Norwalk, Burbank, Oxnard, Simi Valley, Ventura, Camarillo, Newbury Park, Moorpark, Santa Paula, Port Hueneme, Ojai, Whittier, Van Nuys, North Hollywood.

Geofence: Los Angeles County and Ventura County.

Los Angeles County:

https://www.google.com/maps/place/Los+Angeles+County,+CA/@ 34.0923658,$119.2669184,8.75 \mathrm{z} / \mathrm{data}=! 4 \mathrm{~m} 5 ! 3 \mathrm{~m} 4 ! 1 \mathrm{~s} 0 \times 80 \mathrm{dd} 2 \mathrm{ad} 30164 \mathrm{~cd} 31: 0 \times 837 \mathrm{~d} 28 \mathrm{~d} 6 \mathrm{cfbd} 3$ $92 \mathrm{a} ! 8 \mathrm{~m} 2 ! 3 \mathrm{~d} 34.0522265$ !4d-118.2436596.

Ventura County: https://www.google.com/maps/place/Ventura+County,+CA/@34. 0963627,-120.1756938,8z/data $=$ !4m5!3m4!1s0x80e962d2b20077a9:0xdd9590f047c3b 0b3!8m2!3d34.3704884!4d-119.1390642.

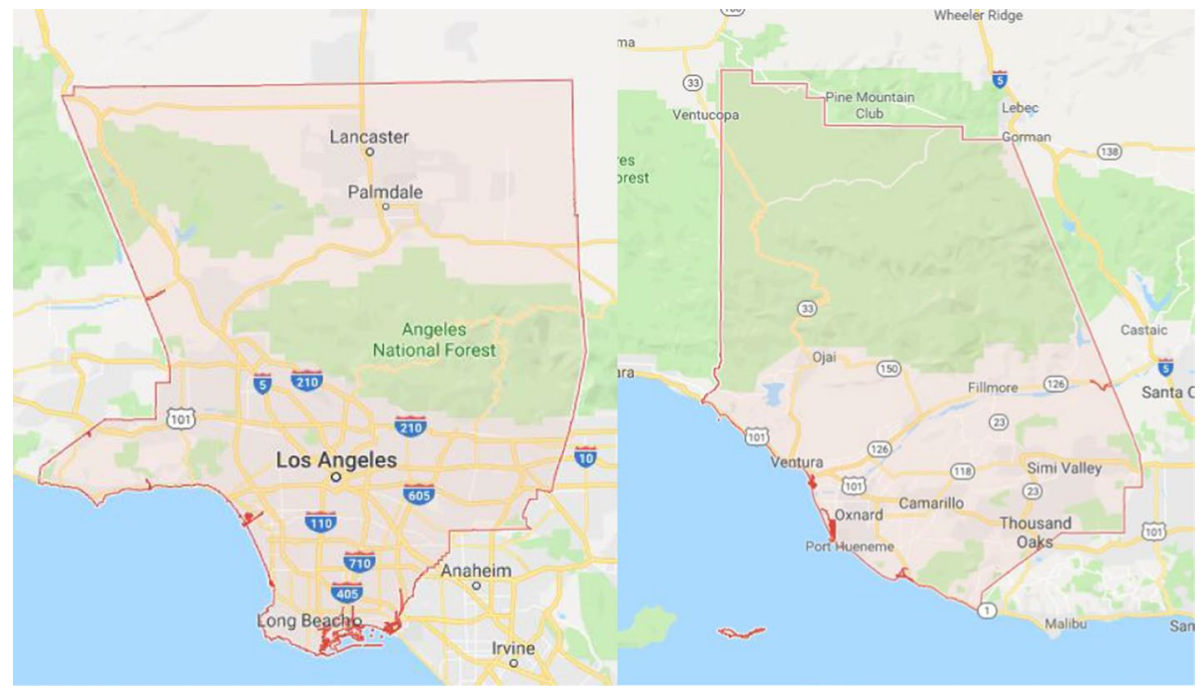


Geofence.

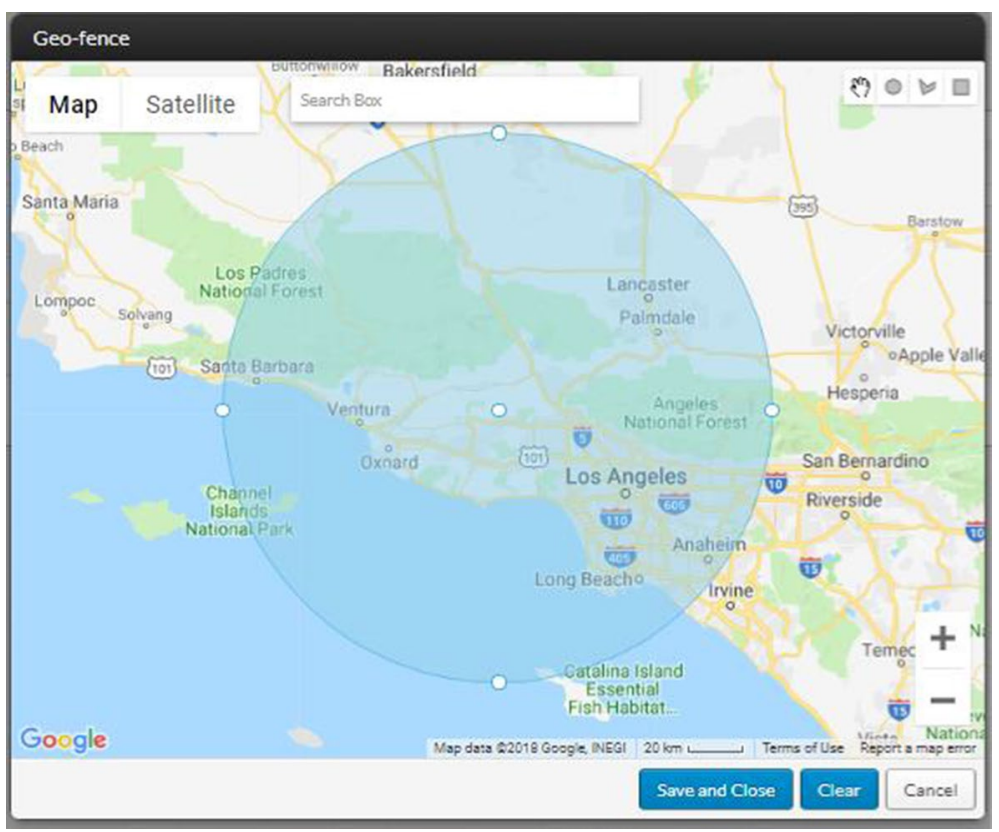

\section{Carr fire-specific terms}

Include term: Carr fire, \#Carrfire, \#CarrFire.

Carr fire during date range: July 23, 2018-August 31, 2018.

Carr fire after date range: September 1, 2018-October 31, 2018.

Carr fire area *all available cities in Shasta County, Trinity County, California.

https://www.worldatlas.com/na/us/ca/c-shasta-county-california.html.

https://www.worldatlas.com/na/us/ca/c-trinity-county-california.html. 
Include geographies: Redding, Anderson, Lake Shasta.

Geofence: Shasta County and Trinity County, California.

\section{Shasta County:}

https://www.google.com/search?rlz=1C1GGRV_enUS757US757\&ei=_8oKXJzZLcv PjwSL_rbwBA\&q=shasta+county+map\&oq=shasta+county+map\&gs_l=psy-ab.3..35i39 j013j0i22i3016.2667.3117..3366...0.0..0.88.336.4.....0....1..gws-wiz......0i71j0i67j0i131 j0i20i263.Ktyuvb0RcV4.

\section{Trinity County:}

https://www.google.com/maps/place/Trinity+County,+CA/@ 40.6712222,-123. $5951061,9 \mathrm{z} / \mathrm{data}=! 3 \mathrm{~m} 1$ ! 4b1!4m5!3m4! 1s0x54d2148e7c7152b5:0x492e195d 1bbba ea6!8m2!3d40.6329485!4d-123.0622553.
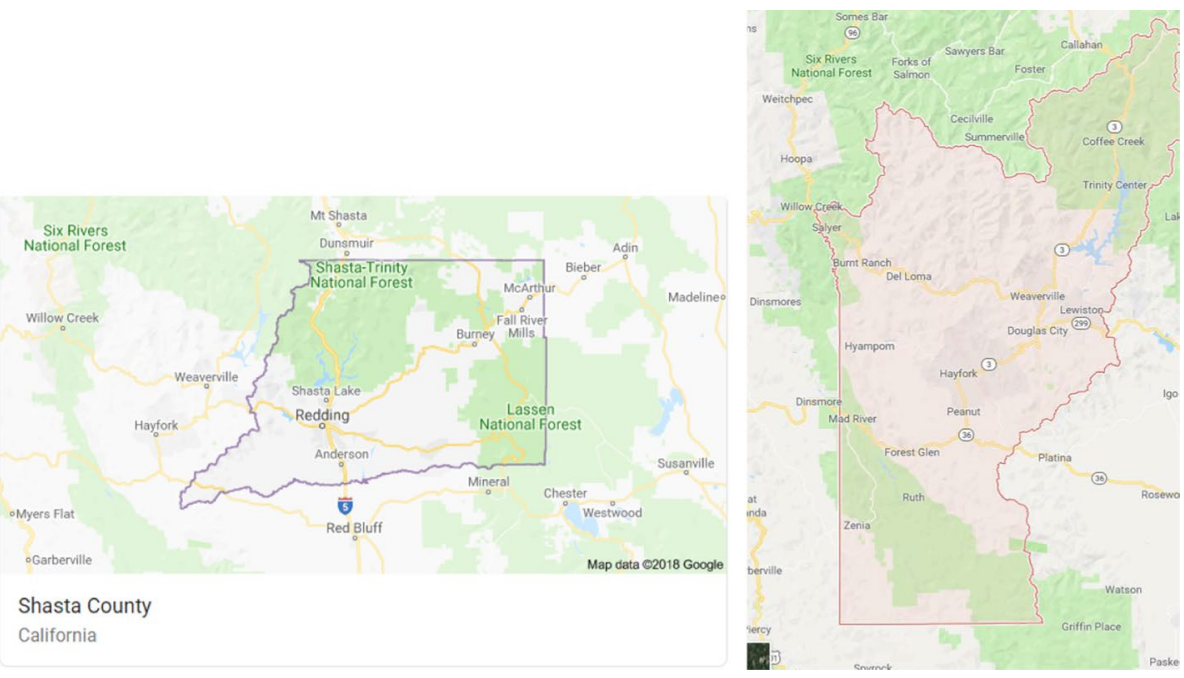

Geofence. 


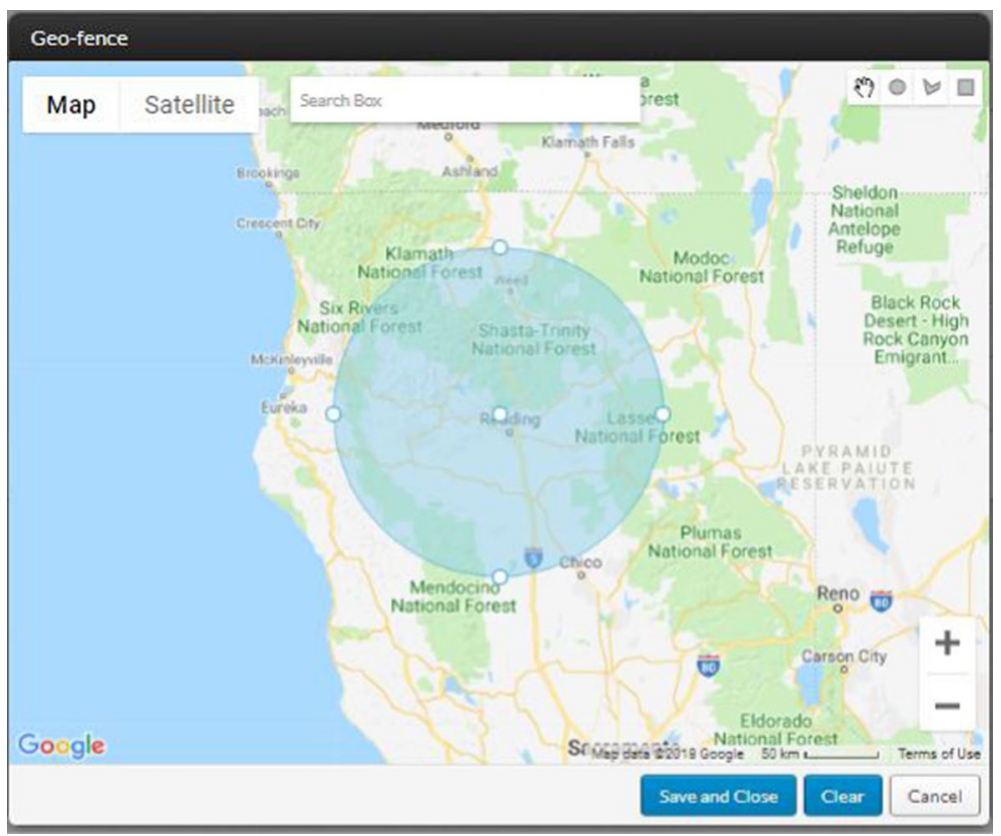

\section{Mendocino Complex fire-specific terms}

Include term: Mendocino Complex fire, \#MendocinoFire, \#Mendocinofire, \#Mendocinocomplexfire, \#MendocinoComplexFire.

Mendocino Complex fire during date range: July 27, 2018-October 04, 2018.

Mendocino Complex fire after date range: October 05, 2018-December 4, 2018.

Mendocino Complex fire area *all available cities in Colusa County, Glenn County, Lake County, Mendocino County; California.

https://www.worldatlas.com/na/us/ca/c-colusa-county-california.html.

https://www.worldatlas.com/na/us/ca/c-glenn-county-california.html.

https://www.worldatlas.com/na/us/ca/c-lake-county-california.html.

https://www.worldatlas.com/na/us/ca/c-mendocino-county-california.html.

Include geographies: Williams, Orland, Willows, Clearlake, Ukiah.

Geofence Colusa County, Glenn County, Lake County, Mendocino County. 
Colusa County: https://www.google.com/maps/place/Colusa+County,+CA/@39.15267 64,-122.1389416,9.25z/data $=! 4 \mathrm{~m} 13 ! 1 \mathrm{~m} 7 ! 3 \mathrm{~m} 6 ! 1 \mathrm{~s} 0 \times 80837 \mathrm{eeb} 7 \mathrm{~d} 4 \mathrm{~d} 3 \mathrm{e} 45: 0 x 29 \mathrm{ab} 73 \mathrm{~b} 8$ d3d7ea34!2sColusa+County,+CA!3b1!8m2!3d39.1040645!4d-122.2653887!3m4!1s0x8 0837eeb7d4d3e45:0x29ab73b8d3d7ea34!8m2!3d39.1040645!4d-122.2653887.

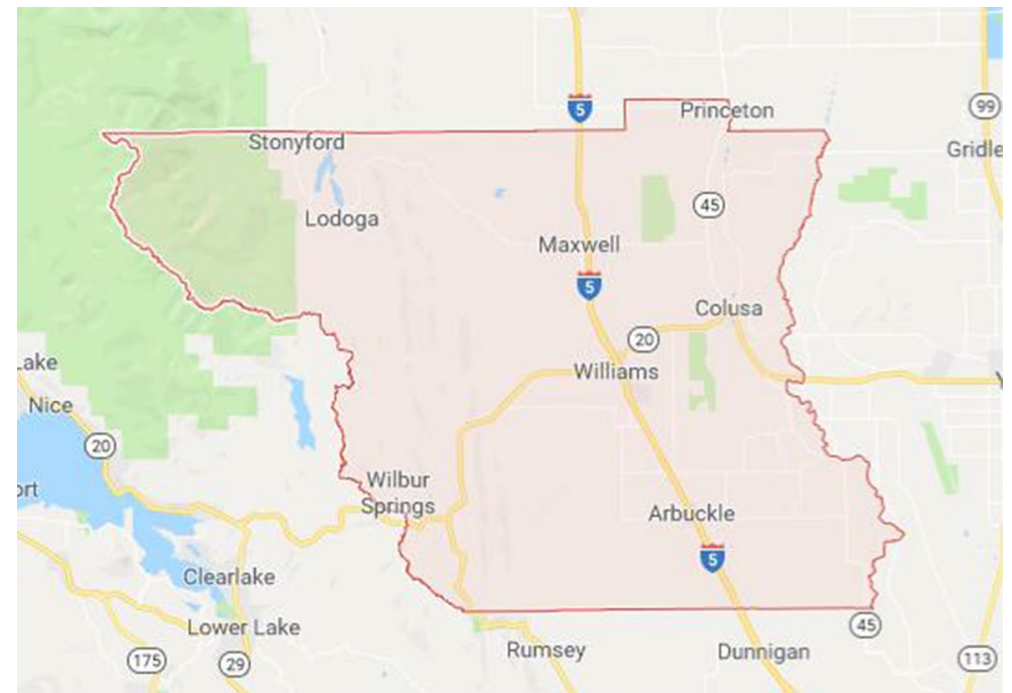

Glenn County: https://www.google.com/maps/place/Glenn+County,+CA/@39.5904073,122.9578337,9z/data $=! 3 \mathrm{~m} 1$ ! 4b1 !4m5!3m4!1s0x8082571656c4308f:0xcc5b77cde 9471 bee!8m2!3d39.6437813!4d-122.4467238.

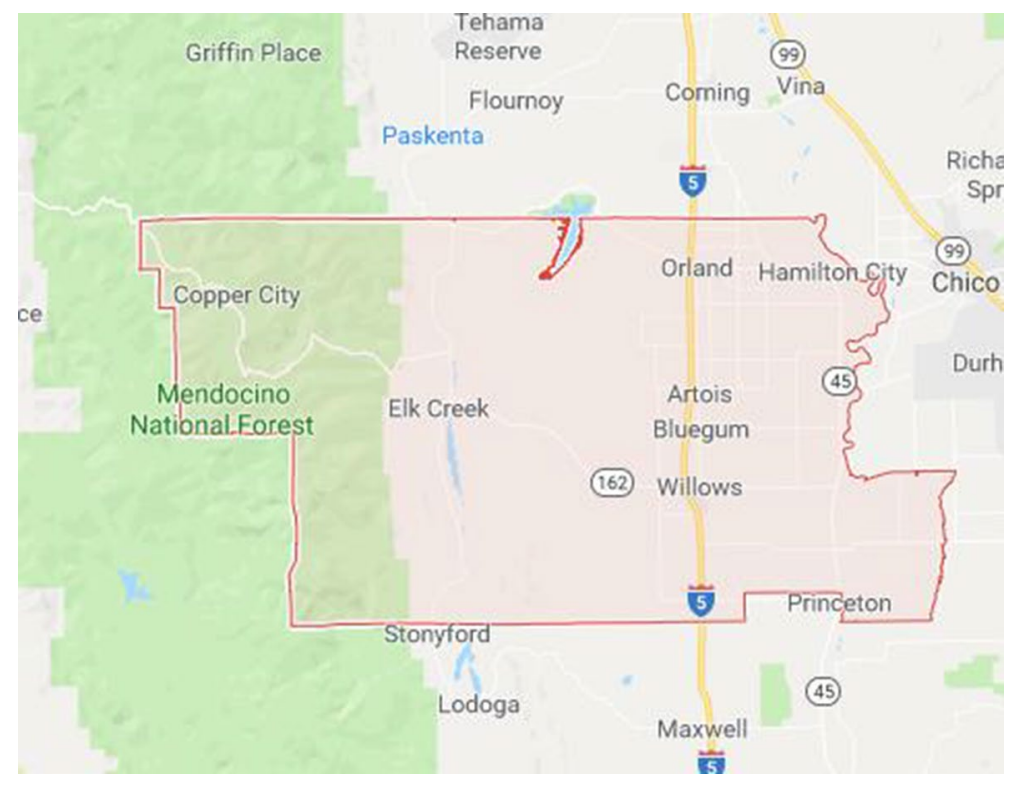




\section{Lake County:}

https://www.google.com/maps/place/Lake+County,+CA/@39.1231112,-123.2776318,9z/ data $=$ !3m1!4b1!4m5!3m4!1s0x8083dd999b415793:0x 89fea1db4886beff!8m2!3d39. 0839644 !4d-122.8084496.

Mendocino County: https://www.google.com/maps/place/Mendocino+County,+CA/@ $39.3789503,-124.0385592,9 \mathrm{z} / \mathrm{data}=! 3 \mathrm{~m} 1$ ! $4 \mathrm{~b} 1 ! 4 \mathrm{~m} 5 ! 3 \mathrm{~m} 4 ! 1 \mathrm{~s} 0 \times 80818 \mathrm{e} 30 \mathrm{be} 51 \mathrm{e} 887: 0 \times 236$ $7 b 369 f 26 \mathrm{e} 0115$ ! $8 \mathrm{~m} 2$ !3d39.5500194!4d-123.438353.

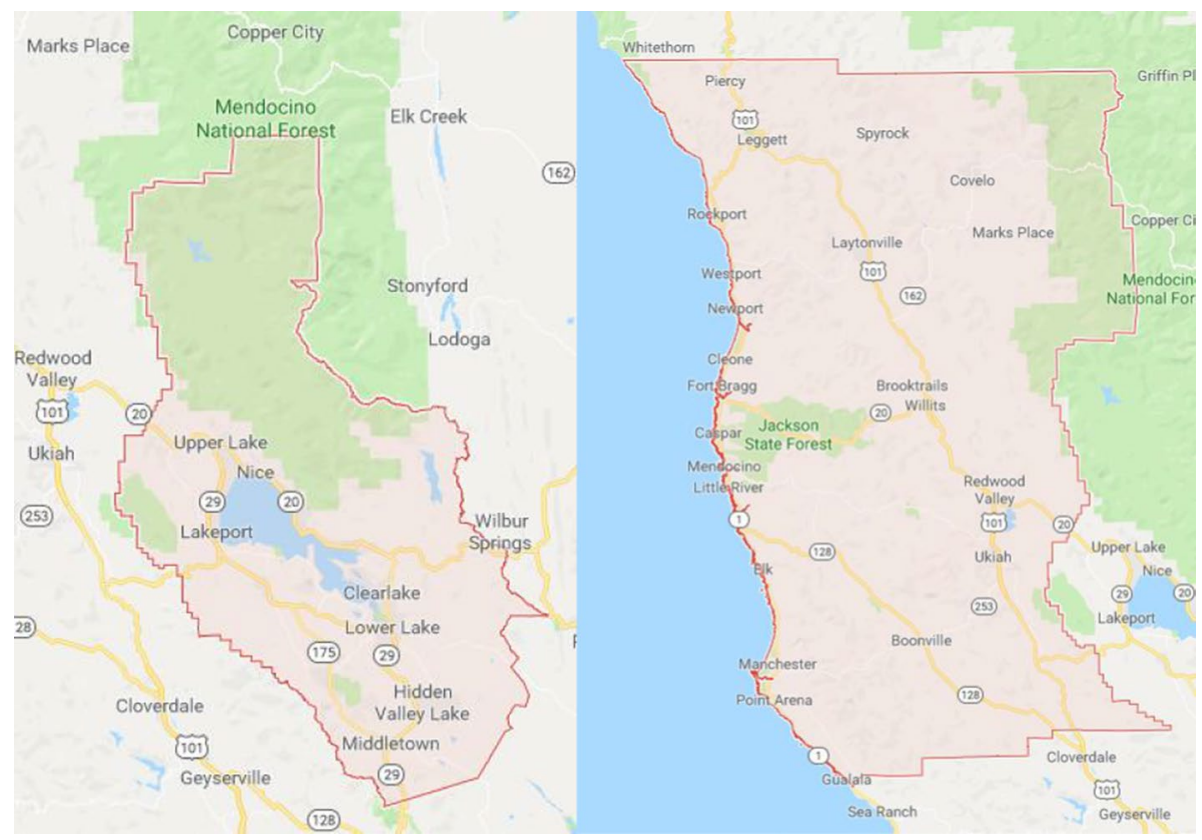

Geofence. 


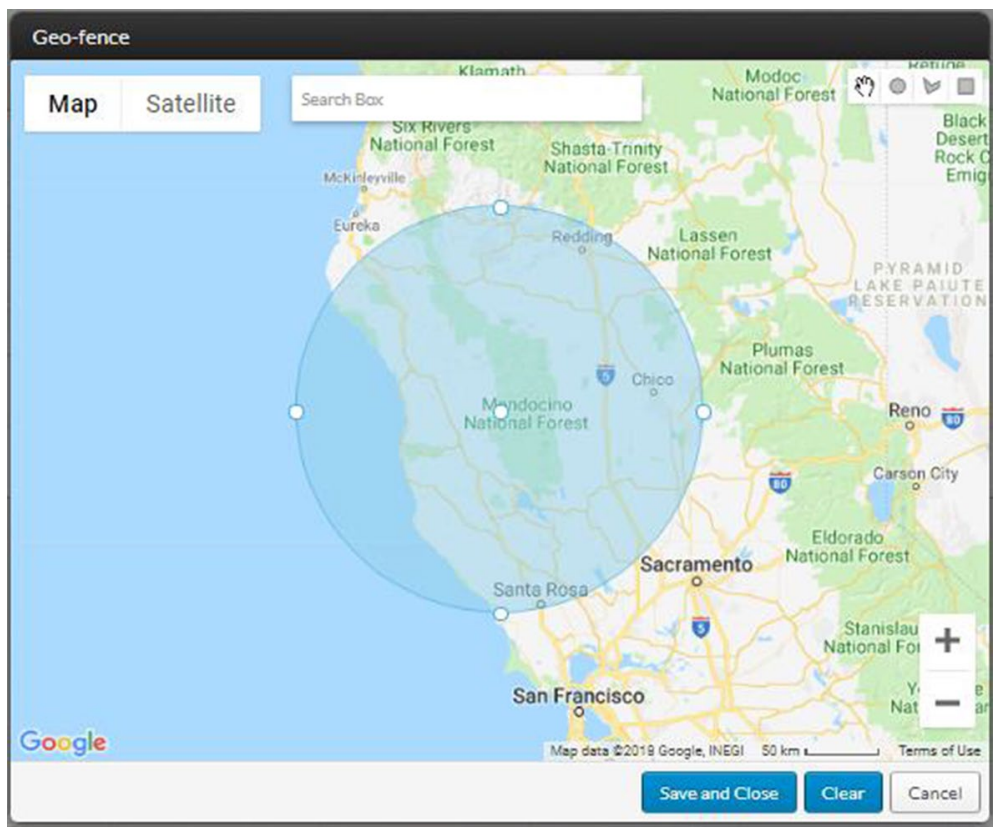

Acknowledgements The authors thank McKenna Clifford for participating in the fruitful discussions that led to the eventual construct of this study.

Funding This work was supported by the USDA National Institute of Food and Agriculture, Hatch Project 1003545 .

\section{Declarations}

Conflict of interest The authors declare that there is no conflict of interest.

\section{References}

Abatzoglou JT, Williams AP (2016) Impact of anthropogenic climate change on wildfire across western US forests. Proc Natl Acad Sci 113(42):11770-11775. https://doi.org/10.1073/pnas.1607171113

Acock ACA (2018) Gentle introduction to stata, 6th edn. Stata Press, College Station

Alexander DE (2014) Social media in disaster risk reduction and crisis management. Sci Eng Eth 20(3):717-733. https://doi.org/10.1007/s11948-013-9502-z

Andrews P, Finney M, Fischetti M (2007) Predicting wildfires. U.S. Forest Service. https://www.fs.usda. gov/treesearch/pubs/29070 Accessed 26 Feb 2020

Avvenuti M, Cresci S, La Polla MN, Meletti C, Tesconi M (2017) Nowcasting of earthquake consequences using big social data. IEEE Internet Comput 21:37-45. https://doi.org/10.1109/MIC.2017.265102211

Blake ES (2018) The 2017 Atlantic hurricane season: catastrophic losses and costs. Weatherwise 71(3):2827. https://doi.org/10.1080/00431672.2018.1448147

Boghani P (2019) Camp fire: by the numbers. Frontline. https://www.pbs.org/wgbh/frontline/article/campfire-by-the-numbers/ Accessed 22 Feb 2020

Cajun Navy (2019) The Cajun Navy relief and rescue. https://www.cajunnavyrelief.com/ Accessed 21 Sep 2019

Cal Fire (2018) Incident information. http://www.fire.ca.gov/current_incidents/incidentdetails/Index/1922 Accessed 21 Sep 2019 
Cameron MA, Power R, Robinson B, Yin J (2012) emergency situation awareness from twitter for crisis management. In: Proceedings of the 21st international conference on world wide web, pp 695-698. https://doi.org/10.1145/2187980.2188183

Cangialosi J, Berg R (2012) Hurricane life cycle and hazards. National Hurricane Center; National Hurricane Conference March, 26, 2012. https://www.nhc.noaa.gov/outreach/presentations/2012_02nhc L311_hurricaneLifeCycleHazards.pdf

Carr J, Decreton L, Qin W, Rojas B, Rossochacki T, Wen Yang Y (2015) Social media in product development. Food Qual Prefer 40:354-364. https://doi.org/10.1016/j.foodqual.2014.04.001

CBSa (2018) Florence gone but its flooding a crisis in parts of North Carolina-live updates. CBS News. https://www.cbsnews.com/live-news/hurricane-florence-aftermath-weather-flooding-power-outagedeath-toll-fema-latest-forecast-live/ Accessed 26 Feb 2020

CBSb (2018) Death toll hits 56 is California's Camp Fire as officials release list of unaccounted, California wildfire fast facts. CBS News. https://www.cbsnews.com/live-news/california-fires-camp-woolseycontainment-evacuations-death-toll-2018-11-14-live-updates/ Accessed 26 Feb 2020

Conway M (2019) Donor intent, disaster relief, education, and policy. Touro L Rev 35:917

Cooper R (2018) Hurricane Florence recovery recommendations. https://files.nc.gov/ncosbm/documents/ files/Florence_Report_Full.pdf Accessed 22 Feb 2020

Kempton SD (2019) Racialized reporting: newspaper coverage of Hurricane Harvey vs. Hurricane Maria. Environ Commun. https://doi.org/10.1080/17524032.2019.1680409

Dowd K (2018) How did the Camp Fire start? SFGate. https:/www.sfgate.com/california-wildfires/article/ cause-butte-county-california-wildfire-source-13395622.php Accessed 22 Feb 2020

Duggan M, Brenner J (2013) The demographics of social media users, 2012, vol 14. Pew Research Center's Internet \& American Life Project, Washington, DC

Earle P (2010) Earthquake Twitter. Nat Geosci 3(4):221-222. https://doi.org/10.1038/ngeo832

FEM (2018a) Florida Hurricane Michael (DR-4399). https://www.fema.gov/disaster/4399 Accessed 12 March 2020

FEMA (2018b) 2017 Hurricane season FEMA after-action report. https://www.fema.gov/media-libra ry-data/1531743865541-d16794d43d3082544435e1471da07880/2017FEMAHurricaneAAR.pdf. Accessed 12 March 2020

FEMA (2019a) Individual disaster assistance. https://www.fema.gov/individual-disaster-assistance Accessed 26 Feb 2020

FEMA (2019b) FEMA public assistance program and policy guide (PPAPG). https://www.fema.gov/medialibrary/assets/documents/111781 Accessed 26 Feb 2020

FEMA (2020) About the agency. https://www.fema.gov/about-agency Accessed 26 Feb 2020

Fischetti M (2018) New data: hurricanes will get worse. Scientific America. https://www.scientificamerican. com/article/new-data-hurricanes-will-get-worse/ Accessed 21 Sep 2020

Freberg K, Saling K, Vidoloff KG, Eosco G (2013) Using value modeling to evaluate social media messages: the case of Hurricane Irene. Public Relat Rev 39:185-192. https://doi.org/10.1016/j.pubrev. 2013.02.010

Imran M, Elbassuoni S, Castillo C, Diaz F, Meier P (2013) Extracting information nuggets from disasterrelated messages in social media. In Iscram.

Insurance Information Institute (III) (2018) Top 10 most wildfire prone states. https://www.iii.org/tablearchive/74507. Accessed 3 Dec 2019

Hamilton M, Tchekmedyian A, Oreskes B, Nelson LJ, Cosgrove J (2018) As toll mounts from Malibu to Thousand Oaks, how did the Woolsey fire become a monster? Los Angeles Times. https://www.latim es.com/local/lanow/la-me-woolsey-fire-spread-20181113-story.html Accessed 19 Dec 2019

Halverson JB (2018) The costliest hurricane season in U.S. history. Weatherwise 71:20-27. https://doi.org/ 10.1080/00431672.2018.1416862

Hurricanes: Science and Society. Hurricane life cycle. http://www.hurricanescience.org/science/science/ hurricanelifecycle/. Accessed 28 Feb 2020

Kibanov M, Stumme G, Amin I, Lee JG (2017) Mining social media to inform peatland fire and haze disaster management. Soc Netw Anal Min 7(1):30

Kryvasheyeu Y, Chen H, Obradovich N, Moro E, Van Hentenryck P, Fowler J, Cebrian M (2016) Rapid assessment of disaster damage using social media activity. Sci Adv 2(3):e1500779. https://doi.org/10. 1126/sciadv. 1500779

Larino J (2018) Hurricane Florence forms in the Atlantic Ocean, but currently poses no threat to land. NOLA. https://www.nola.com/hurricane/index.ssf/2018/09/hurricane_florence_forms_atlan.html. Accessed 4 Dec 2019

LexisNexis (2019) Dig into new archives for deep insights. https://www.lexisnexis.com/en-us/products/ nexis/news-archives.page. Accessed 4 Dec 2018 
Liu W, Lai C, Xu W (2018) Tweeting about emergency: A semantic network analysis of government organizations' social media messaging during Hurricane Harvey. Public Relat Rev 44(5):807-819. https:// doi.org/10.1016/j.pubrev.2018.10.009

Livingston M, Grad S (2018) Thomas fire, California's largest on record, finally $100 \%$ contained. Los Angeles Times. https://www.latimes.com/local/lanow/la-me-thomas-fire-contained-20180112-story.html. Accessed 19 Dec 2019

Ma A (2018) Instagram influencers are using hashtags about the devastating California wildfires to promote products. Business Insider. https://www.businessinsider.com/instagram-influencers-hashtag-californiawildfires-to-promote-products-2018-11. Accessed 12 Mar 2020

Martin Y, Li Z, Cutter SL (2017) Leveraging Twitter to gauge evacuation compliance: spatiotemporal analysis of Hurricane Matthew. PLoS ONE 12(7):e0181701. https://doi.org/10.1371/journal.pone.0181701

Mendoza M, Poblete B, Valderrama I (2019) Nowcasting earthquake damages with Twitter. EPJ Data Sci 8(1):3. https://doi.org/10.1140/epjds/s13688-019-0181-0

Middleton SE, Middleton L, Modafferi S (2014) Real-time crisis mapping of natural disasters using social media. IEEE Intell Syst 29(2):9-17. https://doi.org/10.1109/MIS.2013.126

Moore FC, Obradovich N (2020) Using remarkability to define coastal flooding thresholds. Nat Commun 11:530. https://doi.org/10.1038/s41467-019-13935-3

Morning Addition (2018) How do wildfires get their names? The national park service explains. NPR. https://www.npr.org/2015/08/26/434821450/how-do-wildfires-get-their-names-the-national-park-servi ce-explains. Accessed 21 Sep 2019

Morris A (2018) Understaffed and overworked: firefighters exhausted by severe California Fires. NPR. https://www.npr.org/2018/11/25/668716885/understaffed-and-overworked-firefighters-exhausted-bysevere-california-fires. Accessed 5 Mar 2020

Nagar S, Seth A, Joshi A (2012) Characterization of social media response to natural disasters. In: Proceedings of the 21st international conference on world wide web, pp 671-674. https://doi.org/10.1145/ 2187980.2188177

Netbase (2018) About NetBase. https://www.netbase.com/about-netbase/. Accessed 4 Dec 2018

Niles MT, Emery BF, Reagan AJ, Dodds PS, Danforth CM (2019) Social media usage patterns during natural hazards. PLoS ONE. https://doi.org/10.1371/journal.pone.0210484

NOAA (2018a) Why do we name tropical storms and hurricanes? https://oceanservice.noaa.gov/facts/ storm-names.html. Accessed 4 Dec 2018

NOAA (2018b) National Hurricane Center. https://www.nhc.noaa.gov/data/tcr/index.php?season=2018\& basin=atl. Accessed 4 Dec 2018

NOAA (2018c) Hurricane research division frequently asked questions. http://www.aoml.noaa.gov/hrd/ tcfaq/E19.html. Accessed 4 Dec 2018

NOAA (2018d) Assessing the U.S. climate in 2018. https:/www.ncei.noaa.gov/news/national-climate201812. Accessed 4 Dec 2018

Ortiz DA (2018) Five myths about wildfires. BBC. https://www.bbc.com/future/article/20181113-fivemyths-about-wildfires. 25 Feb 2019

Panagiotopoulos P, Bigdeli AZ, Sams S (2014) Citizen-government collaboration on social media: the case of Twitter in the 2011 riots in England. Gov Info Q 31:349-357. https://doi.org/10.1016/j.giq.2013.10.014

Panagiotopoulos P, Barnett J, Bigdeli AZ, Sams S (2016) Social media in emergency management: twitter as a tool for communicating risks to the public. Technol Forecast Soc 111:86-96. https://doi.org/10. 1016/j.techfore.2016.06.010

Perrin A (2015) Social media usage. Pew Research Center, Washington, DC, pp 52-68

Pogrebnyakov N, Maldonado E (2018) Didn't roger that: Social media message complexity and situational awareness of emergency responders. Int J Inf Manag 40:166-174. https://doi.org/10.1016/j.ijinfomgt. 2018.02.004

Pourebrahim N, Sultana S, Edwards J, Gochanour A, Mohanty S (2019) Understanding communication dynamics on Twitter during natural disasters: a case study of Hurricane Sandy. Int J Disast Risk Red 37:101176. https://doi.org/10.1016/j.ijdrr.2019.101176

Reen K (2018) 5 tips for using Twitter during emergencies and natural disaster. Twitter Blog. https://blog. twitter.com/en_sea/topics/insights/2018/5-Tips-for-using-Twitter-during-emergencies-and-naturaldisaster.html Accessed 5 March 2020

Sadri AM, Hasan S, Ukkusuri SV, Cebrian M (2018) Crisis communication patterns in social media during Hurricane Sandy. Transp Res Rec 2672(1):125-137. https://doi.org/10.1177/0361198118773896

Sakaki T, Okazaki M, Matsuo Y (2010) Earthquake shakes Twitter users: real-time event detection by social sensors. In: Proceedings of the 19th international conference on World Wide Web. ACM

Sanchez R (2018) Northern California's deadly Carr Fire fully contained, state officials say. CNN. https:// www.cnn.com/2018/08/31/us/california-carr-fire-contained/index.html. Accessed 4 Dec 2018 
Schoen J, McDonald J (2019) Warming climate, population sprawl threaten California's future with more destructive wildfires. CNBC. https:/www.cnbc.com/2019/11/09/why-californias-wildfires-are-goingto-get-worse.html. Accessed 27 Feb 2020

Solomon S (2018) How does the camp fire compare to other historical wildfires? ABC news. https://www. abc10.com/article/news/local/paradise/how-does-the-camp-fire-compare-to-other-historical-wildfires/ 103-614203229. Accessed 27 Feb 2020

Son J, Lee HK, Jin S, Lee J (2019) Content features of tweets for effective communication during disasters: a media synchronicity theory perspective. Int J Inf Manag 45:56-68. https://doi.org/10.1016/j.ijinf omgt.2018.10.012

StataCorp (2019) Stata statistical software: release 16. StataCorp LLC, College Station

Taylor M, Wells G, Howell G, Raphael B (2012) The role of social media as psychological first aid as a support to community resilience building. Aust J Emerg Manag 27(1):20

Thunström L, Noy S (2019) The value of thoughts and prayers. Proc Natl Acad Sci 116(40):19797-19798

USDA (2020) Wildland fire careers. U.S. Forest Service. https://www.fs.usda.gov/managing-land/fire/caree rs. Accessed 26 Feb 2020

Wang B, Zhuang J (2017) Crisis information distribution on Twitter: a content analysis of tweets during Hurricane Sandy. Nat Hazards 89(1):161-181

Wilson SG, Fischetti TR (2010) Coastline population trends in the United States 1960 to 2008. US Department of Commerce, Economics and Statistics Administration, US Census Bureau, Washington, DC, pp $1-28$

Yin J, Lampert A, Cameron M, Robinson B, Power R (2012) Using social media to enhance emergency situation awareness. IEEE Intellig Syst 27(6):52-59. https://doi.org/10.1109/MIS.2012.6

Publisher's Note Springer Nature remains neutral with regard to jurisdictional claims in published maps and institutional affiliations. 